\title{
近年碳环核苷类似物的合成研究进展
}

\author{
刘亚君郭翔海* 白 鹏* \\ (天津大学化工学院 系统生物工程教育部重点实验室 天津 300072)
}

\begin{abstract}
摘要 碳环核甘是呋喃糖环部分被碳环基团取代的核苷类似物. 作为天然核苷的类似物, 许多碳环核苷具有良好的抗 病毒、抗肿瘤活性. 同时, 由于不存在典型的糖苗键, 碳环核苷较天然核苗对于磷酸化酶和水解酶具有更高的代谢稳定 性. 因此, 对碳环核苷类似物进行设计与合成, 并篮选出安全有效的抗病毒试剂成为近年来药物化学家们研究的重点. 按照碱基种类的不同综述了近 5 年来碳环核苷的合成研究进展, 分为嘌呤类碳环核苷、嘧啶类碳环核苗以及碳环 C-核 苷等三部分，重点介绍了嘌呤类碳环核苷的合成研究，并对碳环核苷未来的研究趋势进行了展望.
\end{abstract}

关键词 碳环核苷; 抗病毒活性; 合成

\section{Recent Progress in the Syntheses of Carbocyclic Nucleosides}

\author{
Liu, Yajun Guo, Xianghai* Bai, Peng* \\ (Key Laboratory of Systems Bioengineering, Ministry of Education, School of Chemical Engineering and Technology,
} Tianjin University, Tianjin 300072)

\begin{abstract}
Carbocyclic nucleosides are nucleoside analogues whose furanose rings are substituted by carbocycles. As analogues, many carbocyclic nucleosides show good antiviral or antitumor activities. Also, due to the absence of a typical glycosidic bond, carbocyclic nucleosides usually exhibit more metabolic stabilities to phosphorylases and hydrolases than natural nucleosides. Therefore, medicinal chemists have focused their attention on designing and preparing new carbocyclic nucleoside analogues, in efforts to discover new more powerful and safe antiviral agents. The syntheses of carbocyclic nucleosides in the past five years classified by different types of bases are reviewed in this article, denoted as purine carbocyclic nucleosides, pyrimidine carbocyclic nucleosides and carbocyclic analogues of C-nucleosides, with an emphasis on the synthesis of purine carbocyclic nucleosides. In the end, the problems and future trends of carbocyclic nucleoside research are discussed. It is still a challenge to intelligently design and efficiently synthesize the novel carbocyclic nucleosides targeted for some special purposes.

Keywords carbocyclic nucleosides; antiviral activity; synthesis
\end{abstract}

在过去的几十年中, 碳环核苷类似物已被广泛研 究, 发现这些物质具有多种生物活性, 尤其是抗病毒和 抗肿瘤活性 ${ }^{[1]}$. 碳环核甘的结构与天然核甘相似, 天然 核苷为嘌呤的 9- $\mathrm{N}$ 或嘧啶的 1-N 与核糖或脱氧核糖的 $1-\mathrm{C}$ 通过 $\beta$ 糖苷键连接而成的化合物. 在发现和合成的 碳环核苷中，具有生物活性的手性碳环核苷大部分为 $\beta$ 异构体, $\alpha$ 异构体具有抗病毒和抗肿瘤活性报道较少. 这些碳环核苷类似物能够被许多酶和受体识别, 并且它 们在磷酸化酶和水解酶的作用下, 对 $\mathrm{C}-\mathrm{N}$ 键裂解有很 高的抵抗性. 此外, 碳环核苷类似物还是很好的细胞激 酶的底物 ${ }^{[2]}$.
从首次发现碳环核苷化合物至今, 已经有一些五元 碳环核苷从天然产物中分离, 并表现出显著的生物学活 性 ${ }^{[3]}$. 一些碳环核苷被成功开发成药物 ${ }^{[4]}$. 但由于现存 核苷类药物普遍存在毒副作用较高、活性较低的缺点 ${ }^{[5]}$, 加之耐药性和流行病毒(艾滋病毒、甲型 $\mathrm{H}_{1} \mathrm{~N}_{1}$ 流感、禽 流感 $\mathrm{H}_{5} \mathrm{~N}_{1}$ 等)的出现, 激发科研人员为寻求新一代的更 有效和选择性更好的核苷类药物而不解努力 ${ }^{[6]}$.

近几年有较多关于碳环核苷类似物合成及其生物 活性的报道, 国内外也发表了几篇关于碳环核苷的综述 类文章 ${ }^{[1,2,6,7]}$. Jeong 等 ${ }^{[1]}$ 综述了以闭环复分解 $(\mathrm{RCM})$ 反 应为关键步骤的碳环假糖和碳环核苷的不对称合成;

\footnotetext{
*E-mail: guoxh@tju.edu.cn

Received May 7, 2014; revised June 10, 2014; published online July 3, 2014.

Project supported by the National Natural Science Foundation of China (No. 21202116).

国家自然科学基金(No. 21202116)资助项目.
} 
Matyugina 等 ${ }^{[2]}$ 从碳环核苷的分类、靶向酶、作用机制 和合成方面进行了综述; Boutureira 等[ [6 综述了对映选择 性合成三元碳环假糖到六元碳环假糖的不同方法. 国内 最近的一篇关于碳环核苷的综述性文章是在 2008 年发 表的 ${ }^{[8]}$, 该文按照碳环大小分类, 综述了近年来各类碳 环核苷的合成研究进展. 由于核苷类化合物的合成和研 究一直是近几年研究的热点, 最近 5 年涌现出大量关于 碳环核苷类似物的合成及抗病毒活性报道, 有必要对该 领域近几年的成果进行重新整理和总结. 本文综述了近 5 年来碳环核苷类似物的合成研究, 为叙述方便且条理 清晰, 本文将按照核苷碱基的不同类别进行总结.

\section{1 嘌呤碳环核苷}

\section{1 嘌呤碳环核苷}

从对碳环核苷开始研究至今, 发现和合成的大部分 碳环核苷的碱基部分均为嘌呤(鸟嘌呤、腺嘌呤)或修饰 的嘌呤(1-脱氮嘌呤、3-脱氮嘌呤、7-脱氮嘌呤、8-氮杂 嘌呤), 六种典型的嘌呤碳环核苷如 Scheme 1 所示. 由 于两个天然碳环核苷(一)-Aristeromycin ${ }^{[9]}$ (1) 和 (-)Neplanocin $\mathrm{A}^{[10]}$ (2) 的发现, 并且其显示出抗菌和抗肿 瘤活性，许多碳环核苷包括 Carbovir ${ }^{[11]}(3)$, Abacavir $^{[4 a]}$ (4) 已经被成功合成. Carbovir (3) 通过 HIV-1 逆转录酶的 选择性抑制显示了显著的抗 HIV 活性. 它的衍生物 Abacavir (4)同样是有效的, 并且因为其毒性较低且具 有较高的口服生物利用度, 已获得食品和药物管理局批 准用于治疗艾滋病. Neplanocin $F^{[12]}$ (5)可以想象成是 Neplanocin A (2)的烯丙基重排的异构体, 比 Neplanocin A (2) 的细胞毒性小得多, 但其生物活性是未知的 ${ }^{[13]}$. 而 Entecavir (6) 具有显著的抗 HBV 活性.

\subsection{1 核糖电子等排体}

核糖电子等排体是指碳环核苷的糖基部分为类似 核糖的结构, 即 2-C, 3-C 和 5-C 的一个氢均被羟基取代 的五元碳环结构. 天然碳环核苷(一)-Aristeromycin (1)
是具有核糖电子等排体的碳环核甘的典型代表.

研究表明, (一)-Aristeromycin (1)的类似物碳环 6-(对甲基市硫基)肌苷(15)具有显著的抗弓形虫活性. Kim 等 ${ }^{[14]}$ 以 $D$-核糖(7)为原料合成了 21 种碳环 6-市硫肌 苷类似物, 并对其与弓形虫腺苷激酶的亲和力进行了评 价. 结果表明, 不同芳环上的 6-市硫基取代比未取代的 化合物显示了与酶更高的亲和能力. 其中 6-(对甲基市 硫基)肌苷(15)表现出最有效的亲和力并具有显著的抗 弓形虫活性. 细胞培养中没有任何明显的宿主毒性. 他 们采用 $D$-核糖(7)为起始原料, 经 8 步反应得到化合物 $\mathbf{8}^{[15]}, 8$ 步收率为 54\%. 化合物 8 在锂二(叔丁氧基甲基) 铜氧化物的条件下得到光学纯的单一异构体 $\mathbf{9}^{[16]}$, 收率 为 $87 \%$. 化合物 9 用硼氢化钠进行立体选择性还原, 得 到相应的醇 10 , 化合物 10 与甲磺酰氯在三乙胺的存在 下, 得到化合物 11 , 然后将化合物 11 与叠氮化钠在 DMF 中和 $150{ }^{\circ} \mathrm{C}$ 温度下反应得到叠氮基碳环化合物 12. 化合物 12 经过还原、耦合及环化作用得到 6-氯嘌 呤衍生物 13, 化合物 13 与硫腿在乙醇中反应得到对应 的硫酮，接着在三氟乙酸水溶液下脱保护得到 6-颈基嘌 呤衍生物 14. 他们采用了溶液相平行合成法使关键中 间体 14 与适当的芐基卤化物反应得到碳环核苷类似物 15 (Scheme 2).

\subsection{2 其他糖电子等排体}

其他糖电子等排体是指碳环核苷的糖基部分为非 核糖结构的碳环衍生物, 既包括研究较多的五元碳环核 苷，也包括其他碳环核苷(包括三元、四元、六元、七元 以及双环碳环核苷). Carbovir (3), Abacavir (4), Neplanocin F (5) 以及 Entecavir (6)均为非核糖电子等排体的碳 环核苷的代表. 天然碳环核苷(一)-Aristeromycin (1)和 (一)-Neplanocin A (2)虽然有显著的抗病毒活性, 但由于 他们可以在腺苷激酶的催化下发生磷酸化, 对宿主细胞 产生毒性 ${ }^{[17]}$, 因此对天然核苷的改造从而降低其毒副 作用成为近年来研究的重点.<smiles>[Z6]C1C=C(CO)[C@@H](O)C1n1cnc2c(N)ncnc21</smiles><smiles>Nc1nc2c(ncn2C2C=CC(CO)C2)c(=O)[nH]1</smiles>

3<smiles>C=C1C(CO)[C@@H](O)C[C@H]1n1cnc2c(=O)[nH]c(N)nc21</smiles><smiles>Nc1nc(NC2CC2)c2ncn(C3C=CC(CO)C3)c2n1</smiles>

4

Scheme 1 


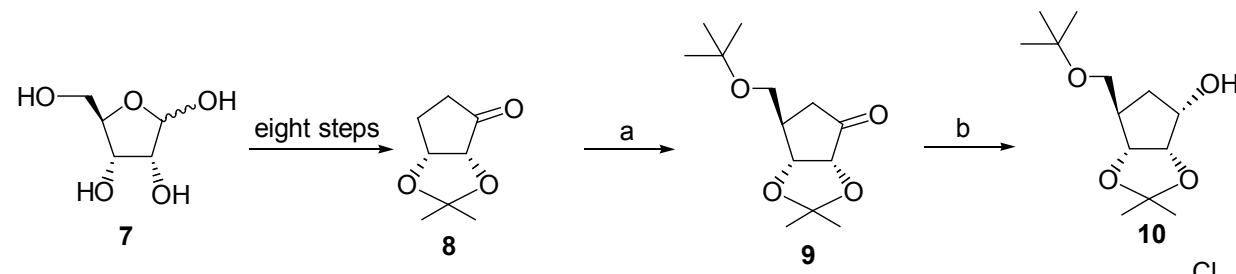<smiles>[Z10]C1(C)O[C@H]2C(N)CC(COC(C)(C)C)[C@H]2OC1(C)OC(C)C</smiles><smiles>Cc1ccc(CSc2ncnc3c2ncn3[C@@H]2C[C@H](CO)[C@@H](O)[C@H]2O)cc1</smiles>

Reagents and conditions: (a) $(t \text {-BuOCH})_{2} \mathrm{CuLi}_{2} t$-BuOMe/THF, $-30{ }^{\circ} \mathrm{C}, 30 \mathrm{~min}$; (b) $\mathrm{NaBH}_{4}, \mathrm{MeOH}, 0{ }^{\circ} \mathrm{C}, 1 \mathrm{~h}, 96 \%$; (c) $\mathrm{MsCl} \mathrm{Et}_{3} \mathrm{~N}, \mathrm{CH}_{2} \mathrm{Cl}_{2}, 0$ ${ }^{\circ} \mathrm{C}, 1 \mathrm{~h}, 92 \%$; (d) $\mathrm{NaN}_{3}$, DMF, $150{ }^{\circ} \mathrm{C}, 6 \mathrm{~h}, 85 \%$; (e) $\mathrm{H}_{2}, 10 \% \mathrm{Pd} / \mathrm{C}, \mathrm{MeOH}, 207 \mathrm{kPa}, 2 \mathrm{~h}$; (f) 5-amino-4,6-dichloropyrimidine, Et ${ }_{3} \mathrm{~N}, n-\mathrm{PrOH}$, reflux, $24 \mathrm{~h}, 68 \%$ (two steps); (g) $\mathrm{CH}(\mathrm{OEt})_{3}, p-\mathrm{TsOH}$, r.t., $14 \mathrm{~h}, 65 \%$; (h) thiourea, EtOH, reflux, $3 \mathrm{~h}$; (i) TFA/ $\mathrm{H}_{2} \mathrm{O}(\mathrm{V}: \mathrm{V}=2: 1), 50{ }^{\circ} \mathrm{C}, 3 \mathrm{~h}, 52 \%$ (two steps); (j) appropriate benzylhalide, $\mathrm{NH}_{4} \mathrm{OH} / \mathrm{H}_{2} \mathrm{O}$, r.t., $11 \mathrm{~h}$

\section{Scheme 2}

\subsubsection{1 五元碳环核苷}

其他糖电子等排体的五元碳环核苷中, 对 Neplanocin A (2), Carbovir (3), Abacavir (4)和 Neplanocin $\mathrm{F}(5)$ 类似物的合成研究较多. Ye 等 ${ }^{[18]}$ 以 $D$-核糖(7)为原 料成功合成 Neplanocin 类似物 21 和 22 . 合成的关键步 骤包括烯炔复分解和区域选择性氧化. 合成以受保护的 乙二醇烯醛 16 开始, 化合物 16 可以廉价的 $D$-核糖(7) 为原料经过三步进行大规模制备 ${ }^{[19]}$. 乙炔基溴化镁加 成到烯醛 16 得到烯炔, 再将其保护成其叔丁基二甲基 硅烷衍生物 17. 化合物 17 经过烯炔置换作用得到产物 18. $18 \alpha$ 和 $18 \beta$ 异构体可以在此阶段不进行分离并直接 在下一步骤中使用. 利用 Sharpless 不对称二羟基化中 的一个端部烯烃和内部烯烃之间的不同反应速率, 将化 合物 18 与 AD-混合- $\alpha$ 在缺乏甲烷磺酰胺的条件下反应, 得到高度选择性的产物 19 和 20 . 两种异构体 $(\alpha$ 和 $\beta$ )很 容易通过快速柱色谱分离且同分异构体的比例为 $4: 5$. $\alpha$ 异构体 19 用于合成 Neplanocin A 类似物 21 而 $\beta$ 异构 体 20 则作为合成 Neplanocin $\mathrm{A}$ 类似物 22 的原料 (Scheme 3).

Chattopadhyay 及 Tripathy ${ }^{[20]}$ 以 $(R)-2,3$-环亚己基甘 油醛 23 为原料合成了 Carbovir (3) 的类似物 $(L)-(+)-$ Carbovir (28)和(D)-(一)-Carbovir (29). 这种方法的关键 步骤是甲醛与烯丙基溴化物 24 发生 Luche 的烯丙基化 反应从而得到化合物 $\mathbf{2 5}$ 以及使用格鲁布斯第一代催化

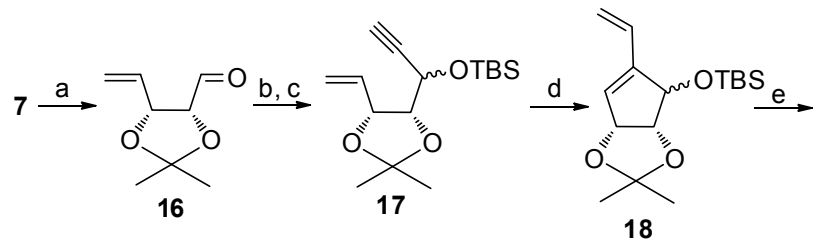<smiles>CO[C@H]1C(C(O)CO)=CC2OC(C)(C)OC21</smiles><smiles>CC(C)(C)OC1C(C(O)CO)=CC2OC(C)(C)OC21</smiles>

19

20<smiles>[AlH][V]</smiles><smiles>Nc1ncnc2c1ncn2[C@@H]1C(CO)=C[C@H](O)[C@H]1O</smiles><smiles>Nc1ncnc2c1ncn2C1C(CCO)=CC(O)C1O</smiles>

Reagents and conditions: (a) (i) $(\mathrm{MeO})_{2} \mathrm{CMe}_{2}, \mathrm{MeOH}$; (ii) $\mathrm{Ph}_{3} \mathrm{P}, \mathrm{I}_{2}$, imidazole; (iii) $\mathrm{Zn}, \mathrm{MeOH}, 68 \%$, three steps from 7; (b) $\mathrm{HC} \equiv$ $\mathrm{CMgBr}$, THF, 86\%; (c) TBSCl, imidazole, $\mathrm{CH}_{2} \mathrm{Cl}_{2}, 83 \%$; (d) first generation Grubbs catalyst, ethylene, $\mathrm{CH}_{2} \mathrm{Cl}_{2}, 86 \%$; (e) AD-mix- $\alpha$, $t-\mathrm{BuOH} / \mathrm{H}_{2} \mathrm{O}, 83 \%$.

\section{Scheme 3}

剂使化合物 26b 发生闭环易位得到化合物 27. 两种异构 
体经过简单的色谱分离, 得到纯手性前体 $27 \mathbf{a}$ 和 $27 \mathbf{b}$. 可以推测, 化合物 27a 和 $\mathbf{2 7 b}$ 或许是他们的另一羟基保 护形式, 将成为合成其他 $2^{\prime}, 3^{\prime}$ - 烯烃的具有 $(L)$-和 $(D)$-构 型的碳环核苷的重要中间体(Scheme 4).

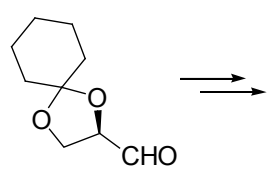

23

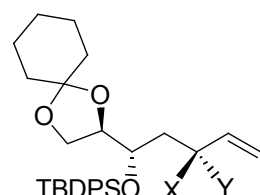

TBDPSŌ X $Y$

25a X $=\mathrm{CH}_{2} \mathrm{OH}, \mathrm{Y}=\mathrm{H}$

25b X $=\mathrm{H}, \mathrm{Y}=\mathrm{CH}_{2} \mathrm{OH}$

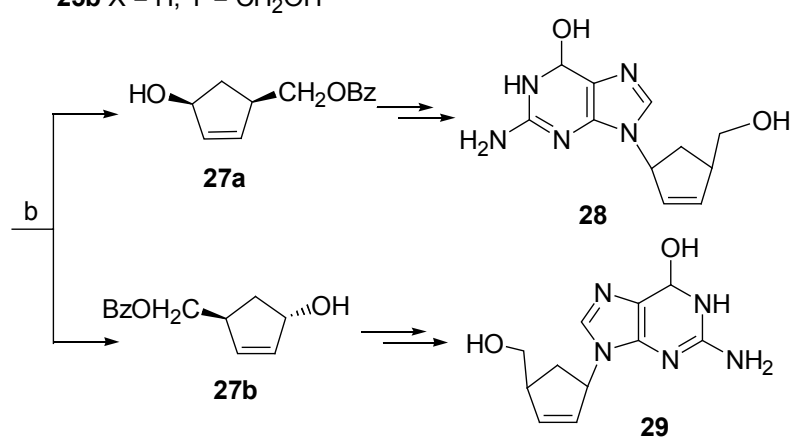

Reagents and conditions: (a) $\mathrm{Zn} / \mathrm{NH}_{4} \mathrm{Cl}, \mathrm{CH}_{2} \mathrm{O}, \mathrm{THF}, 25^{\circ} \mathrm{C}$; (b) $\left.(\mathrm{PCy})_{2}\right)_{2} \mathrm{Cl}_{2} \mathrm{RuCHPh}$, dry benzene, $60{ }^{\circ} \mathrm{C}, 24 \mathrm{~h}$

\section{Scheme 4}

除了对碳环核苷类似物的合成研究, 对已发现的碳 环核苷开发新颖的合成路线也是药物化学家们研究的 热点. Boyle 等 ${ }^{[21]}$ 通过酶法拆分序列手段, 快速不对称 构建核苷的糖片段, 高效合成了对映选择性核甘 (一)-Abacavir(4). 关键中间体为顺式-1,4-取代的环戊烯 32. 起始原料为 $\beta$-内酰胺 $\mathbf{3 0}$, 化合物 $\mathbf{3 0}$ 可由环戊二烯 经过环加成反应得到 ${ }^{[22]}$. 内酰胺 30 在三乙胺和催化剂 4-二甲氨基吡啶(DMAP)的存在下与 4-甲基苯磺酸酐反 应得到化合物 31, 收率为 75\% 81\%. 化合物 31 与 2,6二氯嘌呤四丁铵盐反应，在醋酸钯或三(二亚芐基丙酮) 二钯的催化作用和膦配位体存在下, 于四氢呋喃中常温 反应，以 75\%的收率得到化合物 32 . 化合物 32 用甲基 碘或硫酸二甲酯或 Mitsunobu 条件下进行 $N$-甲基化得到 产物 33, 化合物 33 用嗍氢化钠进行酰氨键裂解还原, 再在回流乙醇中与环丙胺进行杂环胺化反应得到 $\mathbf{3 4}$, 两步收率为 $63 \%$. 化合物 34 与水合肼在甲醇/水混合物 中反应，接着用亚硝酸钠处理得到中间体 35 . 用氯化亚 锡还原 35 即得到最终产物(-)-Abacavir (4), 三步收率 为 $70 \%$ (Scheme 5$)$.
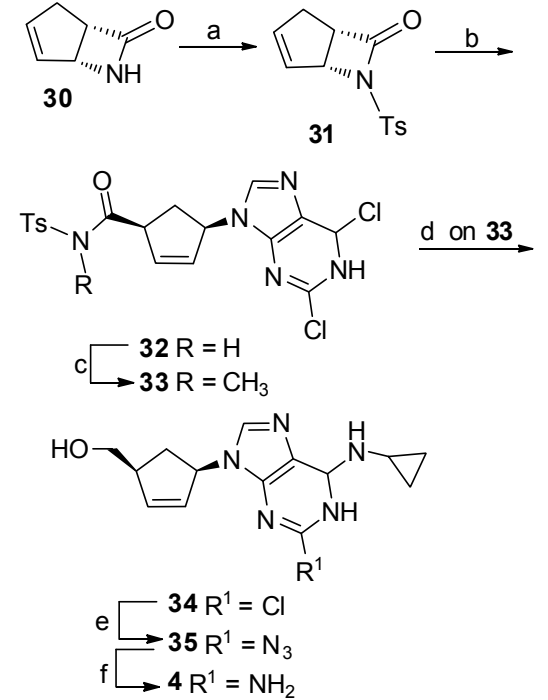

Reagents and conditions: (a) $\mathrm{DCM}, \mathrm{Et}_{3} \mathrm{~N}, \mathrm{DMAP}$ (cat.), then 4-methylbenzenesulfonicanhydride, r.t., $24 \mathrm{~h}$; (b) 2,6-dichloropurine tetrabutylammonium salt, $\mathrm{Pd}_{2}(\mathrm{dba})_{3}, \mathrm{P}(i-\mathrm{OPr})_{3}$, THF, r.t., $90 \mathrm{~min}$, $75 \%$; (c) Mel, $\mathrm{K}_{2} \mathrm{CO}_{3}$, acetone, reflux, $4 \mathrm{~h}, 74 \%$; or dimethylsulfate, $\mathrm{K}_{2} \mathrm{CO}_{3}$, acetone, r.t., $16 \mathrm{~h}, 70 \%$; or $\mathrm{MeOH}, \mathrm{PPh}_{3}$, DIAD, THF, r.t., 94\%; (d) (i) $\mathrm{NaBH}_{4}, i-\mathrm{PrOH} / \mathrm{THF}, 0{ }^{\circ} \mathrm{C}, 1 \mathrm{~h}$ then r.t., $2 \mathrm{~h}, 86 \%$; (ii) cyclopropylamine, EtOH, $50{ }^{\circ} \mathrm{C}, 16 \mathrm{~h}$; (e) $\mathrm{NaNO}_{2}, \mathrm{AcOH} / \mathrm{H}_{2} \mathrm{O}(\mathrm{V}$ : $V=9: 1$ ), $0{ }^{\circ} \mathrm{C}, 1 \mathrm{~h}$; (f) $\mathrm{SnCl}_{2} \cdot 2 \mathrm{H}_{2} \mathrm{O}, \mathrm{EtOH}$, reflux, $2 \mathrm{~h}, 70 \%$ over 3 steps.

\section{Scheme 5}

此外, Schneller 等 ${ }^{[23]}$ 利用缩醛保护环戍烯醇的开环 还原 (二异丁基铝氢化物) 反应合成了非天然的 (+)-Neplanocin F (36)、糖腺苷 2'-氟代 Neplanocin (37) 和 6'-异构体- $L$ 构型 Neplanocin 类似物 38 (Scheme 6).<smiles>Nc1ncnc2c1ncn2C1C(O)C=C(O)C1O</smiles>

36<smiles>Nc1ncnc2c1ncn2C1C=C(CO)C(O)C1F</smiles>

Scheme 6
研究发现, 腺苷通过与 4 种嘌呤 P1 受体 $\mathrm{A}_{1}, \mathrm{~A}_{2 \mathrm{~A}}$, $\mathrm{A}_{2 \mathrm{~B}}$ 和 $\mathrm{A}_{3}$ 的相互作用, 起着调节生理机能的关键作 用 ${ }^{[19]}$. 其中, 腺苷 $A_{2 \mathrm{~A}}$ 受体的激动作用可作为与呼吸系 统疾病哮喘和慢性阻塞性肺病 (COPD) 有关的慢性炎症 的治疗 ${ }^{[24]}$. 迄今为止所有报道的腺苷 $\mathrm{A}_{2 \mathrm{~A}}$ 受体激动剂均 是基于内源性配体腺苷的修饰 ${ }^{[25]}$. Beattie 等 ${ }^{[26]}$ 使用已经 建立的嘌呤替代模式, 确定了两个 4 '-氮杂-碳环核苷系 列, 证明他们具有强有力的和人类腺苷 $\mathrm{A}_{2 \mathrm{~A}}$ 受体激动剂 结合的特性. 其中的 4'-取代基一个是相对于 NECA 羧 酰胺的颠倒的酰胺，另一个是 $\mathrm{N}$-键合的杂环. 其中丙酰 
胺 44 48 和 4-着基甲基吡酰胺 43 为 4'-反转的酰胺和 $4^{\prime}$-键合的杂环系列中最具有选择性的化合物. 他们以 $(1 R, 3 S)$-4-环戊烯-1,3-二醇单乙酸酯(39)为原料, 与嘌呤 衍生物 40 在钯 $(0)$ 催化下发生烯丙基偶联反应, 接着发 生酰化反应得到碳酸乙酯 $\mathbf{4 1}, 41$ 经过第二次钯 $(0)$ 催化 的烯丙基偶联反应和 2,3-双键的羟基化反应得到关键中 间体 42 (Scheme 7).<smiles>CC(C)(C)OC(=O)N(C(=O)OC(C)(C)C)[C@H]1C[C@@H](n2cnc3c2N=C(Cl)NC3Cl)[C@H](O)[C@H]1O</smiles>

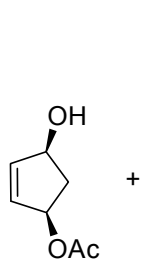

39

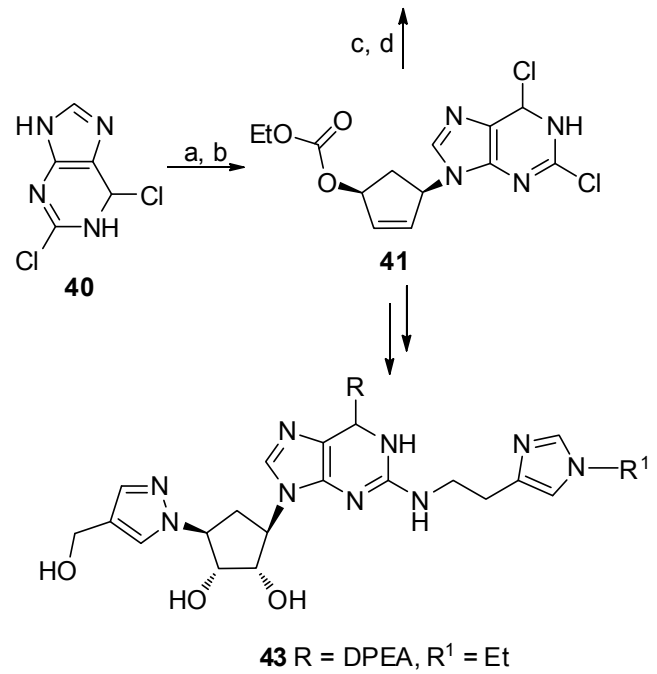<smiles>[R]C(=O)N[C@H]1C[C@@H](n2cnc3c2N=C(NCCc2cn([R])cn2)NC3[R])[C@H](O)[C@@H]1O</smiles>

$44 \mathrm{R}=\mathrm{DPEA}, \mathrm{R}^{1}=\mathrm{H}, \mathrm{R}^{2}=\mathrm{Et}$ $45 \mathrm{R}=\mathrm{DPEA}, \mathrm{R}^{1}=\mathrm{Me}, \mathrm{R}^{2}=\mathrm{Et}$ $46 \mathrm{R}=\mathrm{DPEA}, \mathrm{R}^{1}=\mathrm{Et}, \mathrm{R}^{2}=\mathrm{Et}$ $47 \mathrm{R}=\mathrm{EPA}, \mathrm{R}^{1}=\mathrm{Et}, \mathrm{R}^{2}=\mathrm{Et}$ $48 \mathrm{R}=\mathrm{EPA}, \mathrm{R}^{1}=i-\mathrm{Pr}, \mathrm{R}^{2}=\mathrm{Et}$

Reagents and conditions: (a) 1.0 equiv. $\mathrm{NaH}, 0.05$ equiv. $\left(\mathrm{Ph}_{3} \mathrm{P}\right)_{4} \mathrm{Pd}, 0.15$ equiv. $\mathrm{Ph}_{3} \mathrm{P}$, THF/DMSO ( $\left.V: V=50: 1\right), 2 \mathrm{~h}, 50$ ${ }^{\circ} \mathrm{C}$; (b) 4 equiv. EtOC(O)Cl, 3 equiv. pyridine, THF, $1 \mathrm{~h}, 0{ }^{\circ} \mathrm{C}$ (67\% 75\%); (c) 1.1 eqiuv. (Boc) $)_{2} \mathrm{NH}, 0.05$ equiv. $\mathrm{Pd}_{2}(\mathrm{dba})_{3}, 0.15$ equiv. $\mathrm{Ph}_{3} \mathrm{P}$, THF, 3 h, r.t. $(23 \% \sim 50 \%)$; (d) 0.15 equiv. $\mathrm{OsO}_{4}, 2$ equiv. NMMO, $10: 1 \mathrm{THF} / \mathrm{H}_{2} \mathrm{O}, 18$ h, r.t. $(58 \% \sim 89 \%)$

\section{Scheme 7}

研究表明, 在核苷的 $2^{\prime}$-位引入氟原子可以提高糖 基键对化学和代谢降解的稳定性 ${ }^{[27]}$, 而 Montgomery 等 ${ }^{[28]}$ 证明在碳环糖基引入氟原子可产生有效的抗病毒 剂. 因此, 氟取代的碳环核苷也引起化学家们的研究兴
趣. Singh 等 ${ }^{[29]}$ 合成了 $2^{\prime}-$ 氟-6'-亚甲基的碳环腺苷 (FMCA，55)并对其抗 HBV 活性进行了评价. 就如拉米 夫定、阿德福韦酯和拉米夫定双/恩替卡韦抗突变一样, 碳环腺苷 55 显示了显著的抗病毒活性.

他们以化合物 49 为原料, 而原料 49 可由 $D$-核糖(7) 经 7 步反应合成 ${ }^{[30]}$. 含有烯丙基差基基团的 49 用苄基 保护并脱掉叔丁基保护基得到 50. 接着用 1,3-二氯1,1,2,2-四异丙基选择性保护 $\mathbf{5 0}$, 得到化合物 51, 收率 为 $95 \%$. 化合物 51 和二乙氨基三氟化硫(DAST)反应实 现了 2- $\beta$-差基到 2- $\alpha$-氟代的转变, 得到化合物 52, 收率 为 47\%. 硅烷基用四丁基氟化铵(TBAF)/HOAc 除去，再 将其用苯甲酰氯在吡啶中重新保护, 得到中间体 $\mathbf{5 3}$, 产 率为 $86 \%$. 化合物 53 和三氯化嗍在一 $78{ }^{\circ} \mathrm{C}$ 条件下反应 得到关键中间体 54, 收率为 76\%. 化合物 54 经过缩合、 脱保护及 DIBAL-H 的处理, 得到化合物 55 (Scheme 8).

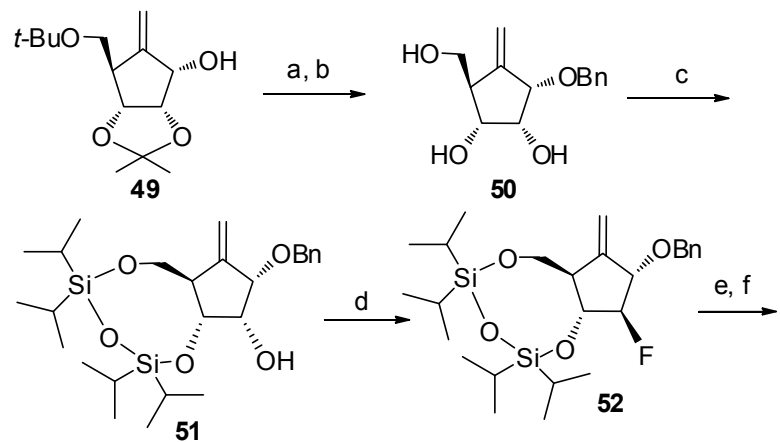

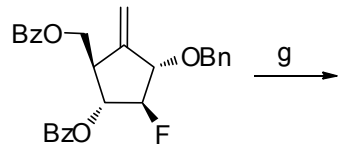

53<smiles>C=C1[C@H](n2cnc3c(N)ncnc32)C(F)[C@@H](O)[C@@H]1O</smiles>

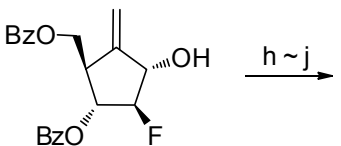

54
Reagents and conditions: (a) $\mathrm{NaH}, \mathrm{BnBr}$, DMF, $0{ }^{\circ} \mathrm{C}$; (b) TFA/ $\mathrm{H}_{2} \mathrm{O}$ $(V: V=2: 1), 50{ }^{\circ} \mathrm{C}$; (c) $\mathrm{TIDPSCl}_{2} /$ imidazole, DMF, $0{ }^{\circ} \mathrm{C}$; (d) DAST, $\mathrm{CH}_{2} \mathrm{Cl}_{2}$, r.t.; (e) TBAF/AcOH, THF, r.t.; (f) BzCl, pyridine, r.t.; (g) $\mathrm{BCl}_{3}, \mathrm{CH}_{2} \mathrm{Cl}_{2},-78{ }^{\circ} \mathrm{C}$; (h) $\mathrm{N}, \mathrm{N}$-dibocprotected adenine, DIAD, $\mathrm{Ph}_{3} \mathrm{P}$, THF, $0{ }^{\circ} \mathrm{C}$; (i) TFA, $\mathrm{CH}_{2} \mathrm{Cl}_{2}$, r.t.; (j) DIBAL-H, $\mathrm{CH}_{2} \mathrm{Cl}_{2}$, $-78^{\circ} \mathrm{C}$

\section{Scheme 8}

关于 2'-氟-6'-亚甲基的碳环腺苷(FMCA) 55 的合成， 除了以化合物 49 为原料的合成方法外，最近 Singh 等 ${ }^{[31]}$ 以市售的 Vince-内酰胺为原料经 16 步合成. 通过合成 关键中间体 D-2'-氟-6'-亚甲基环戊醇，利用 Mitsunobu 偶合反应引入腺嘌呤碱基从而得到最终的核苷.

\subsubsection{2 其他碳环核苷}

五元碳环核苷一直是抗病毒药物研究的重点, 但近 
几年来, 其他碳环核苷(包括三元、四元、六元、七元以 及双环碳环核苷) 也被证实具有抗病毒活性. 下面将简 单介绍近五年来具有代表性的非五元碳环核苷的合成.

研究表明, 碳环核苷的抗病毒活性不仅体现在对 HBV 有效, 一些碳环核苷对 HCV 同样有抵抗作用. Gadthula 等 ${ }^{[30]}$ 应用 Simmons-Smith 环丙烷合成法得到 6环外亚甲基 49, 用于合成新型螺-碳环核苷类似物 60 . 化合物 60 显示了显著的抗 HCV 病毒活性. 以 $D$-核糖 7 为原料经过七步反应 ${ }^{[15,32]}$ 得到化合物 $\mathbf{5 6}$, 化合物 $\mathbf{5 6}$ 和 Eshenmoser 盐反应，接着用霍夫曼降解的方法得到烯酮 57. 烯酮 57 与铈(III)氯化物存在下的硼氢化钠七水合物 反应得到关键中间体 49. 使用二乙基锌和二碘甲烷在 乙醚回流条件下得到关键的螺环中间体 $\mathbf{5 8}, \mathbf{5 8}$ 和 6-氯嘌 呤在 Mitsunobu 条件下偶合得到化合物 $\mathbf{5 9}$, 用氨甲醇饱 和溶液处理并去保护得到目标产物 60 (Scheme 9).
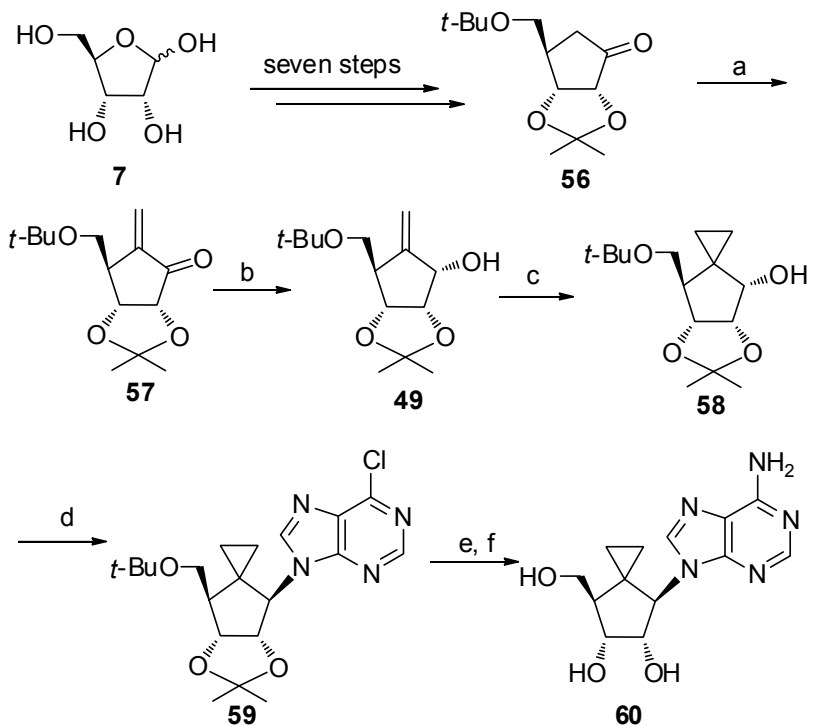

Reagents and conditions: (a) (i) LDA/THF, $-78{ }^{\circ} \mathrm{C}, 3 \mathrm{~h}$; then Eschenmoser's salt, $-78{ }^{\circ} \mathrm{C}, 3$ h, r.t., 8 h; (ii) $\mathrm{CH}_{3} \mathrm{l}, 4$ h, r.t., $10 \%$ $\mathrm{NaHCO}_{3}, 83 \%$; (b) $\mathrm{NaBH}_{4} / \mathrm{CeCl}_{3} \cdot 7 \mathrm{H}_{2} \mathrm{O} / \mathrm{MeOH},-78 \sim 0{ }^{\circ} \mathrm{C}, 90 \%$; (c) $\mathrm{Et}_{2} \mathrm{Zn} / \mathrm{CH}_{2} \mathrm{I}_{2}$, ether, reflux, 93\%; (d) 6-chloropurine, $\mathrm{Ph}_{3} \mathrm{P} / \mathrm{DIAD}$, THF, r.t., 26.6\%; (e) $\mathrm{NH}_{3} / \mathrm{MeOH}, 100{ }^{\circ} \mathrm{C}$, two steps, $48 \%$; (f) TFA $/ \mathrm{H}_{2} \mathrm{O}, 80 \%$.

\section{Scheme 9}

虽然碳环核苷比天然核苷代谢稳定性好 ${ }^{[33]}$, 但亚 甲基对呋喃糖上的氧原子的取代作用引起了其刚性构 象的降低, 从而导致其生物活性降低 ${ }^{[34]}$. 为了克服这个 问题，一些刚性构象的碳环核苷类似物被设计和合成， 包括基于二环 [3.1.0]己烷系统的亚甲基碳环核苷为代表 的核苷 ${ }^{[35]}$. Ji 及 Miller ${ }^{[36]}$ 开发了亚硝基环加成物和重氮 甲烷在乙酸钯催化下的一个高效的和立体选择性的环 丙烷化反应，由此产生的环丙烷化合物是亚甲基碳环核 苷合成的关键中间体. 亚硝基环加成物 61 和重氮甲烷
在醋酸钯的存在下得到外-6-氧杂-7-氮杂三环辛烷衍生 物 62, 化合物 62 在 $10 \% \mathrm{Pd} / \mathrm{C}$ 催化氢化作用下得到 $N$-Boc 保护的 1,4-氨基醇 63. 化合物 64 由化合物 63 在 碱性条件下，经过乙酰化作用得到. 随后经过 TFA-介 导的 $N$-Boc 消除反应得到游离胺 $\mathbf{6 5}$. 最后, 腺嘌呤环作 为代表性的碱基经三步反应得到了 $2^{\prime}, 3^{\prime}$-亚甲基碳环核 苷 68 (Scheme 10).

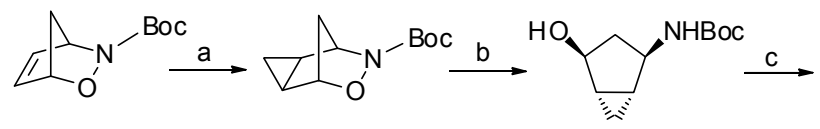

$61 \quad 62 \quad 63$
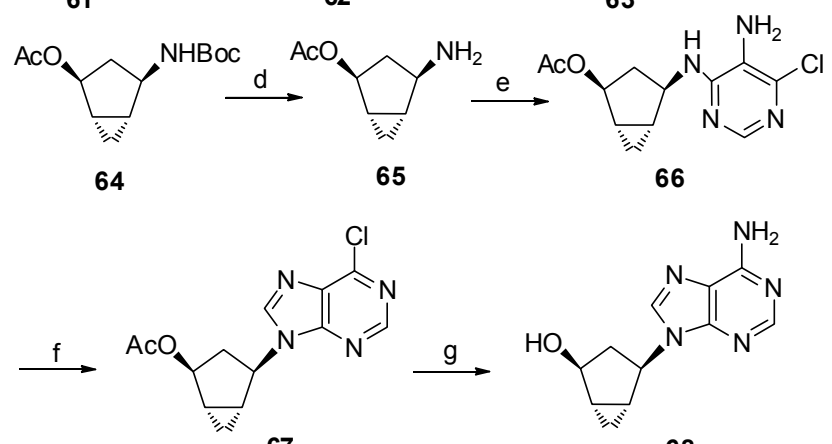

67

68

Reagents and conditions: (a) $\mathrm{Pd}(\mathrm{OAc})_{2}$ (5 mol\%), $\mathrm{CH}_{2} \mathrm{~N}_{2}$ (8 equiv.), $\mathrm{Et}_{2} \mathrm{O}, 0^{\circ} \mathrm{C}, 30 \mathrm{~min}$; (b) $\mathrm{H}_{2}, \mathrm{Pd} / \mathrm{C}, \mathrm{MeOH}$, r.t., 99\%; (c) $\mathrm{Ac}_{2} \mathrm{O}, \mathrm{DMAP}$, pyridine, r.t., 99\%; (d) TFA, $0{ }^{\circ} \mathrm{C}, 1 \mathrm{~h}$; (e) 5-amino-4,6- dichloropyrimidine, $\mathrm{Et}_{3} \mathrm{~N}, n-\mathrm{BuOH}, 110{ }^{\circ} \mathrm{C}, 3 \mathrm{~d}, 32 \%$ from 64 ; (f) $\mathrm{CH}(\mathrm{OEt})_{3}$, CSA, r.t., $75 \%$; (g) $\mathrm{NH}_{3}, \mathrm{MeOH}, 50{ }^{\circ} \mathrm{C}, 74 \%$

\section{Scheme 10}

与 $\mathrm{Ji}$ 及 Miller 合成 2',3'-亚甲基碳环核苷 68 的方法 类似，Moggio 等 ${ }^{[37]}$ 同样用线性合成法成功地合成了一 系列含有葱取代基的异噁唑啉-碳环去甲核苷. 通过评 价其对各种病毒包括乙型肝炎 $(\mathrm{HBV})$ 、丙型肝炎 $(\mathrm{HCV})$ 、 人类乳头状瘤病毒(HPV-11)、A 型流感病毒(FLU-A, 甲 型 $\mathrm{H}_{1} \mathrm{~N}_{1}$ 流感和 $\mathrm{H}_{3} \mathrm{~N}_{2}$ ) 和 B 型流感病毒(FLU-B)的抑制水 平发现，化合物 $\mathbf{7 4}$ 有良好的抗人类乳头状瘤病毒 (HPV-11) 活性且具有较低的细胞毒性, 对乙型肝炎 $(\mathrm{HBV})$ 、丙型肝炎 $(\mathrm{HCV})$ 抗病毒活性适中，而对流感病毒 的抗病毒活性几乎可以忽略不计. 化合物 69 在碱性条 件下水解得到 70, 化合物 70 在 $\mathrm{Pd} / \mathrm{C}$ 催化下氢解得到氨 基化合物 71, 用线性合成法将 71 与 5-氨基-4,6-二氯嘧 啶进行偶联得到 72, 接着与原甲酸三乙酯缩合得到 73, 最后, 化合物 73 的氯原子与乙胺发生亲核取代 得到最终产物 74 (Scheme 11).

另外, Quadrelli 等 ${ }^{[38]}$ 同样运用线性合成法合成含有 喹啉基团的异噁唑啉一碳环去甲核苷，得到一系列腺嘌呤 杂环类似物, 并测试其对各种病毒包括乙肝, PTV 和甲型 流感病毒 $\mathrm{H}_{1} \mathrm{~N}_{1}$ 的抑制活性, 结果表明 75a 和 75b 对 FLU-A 和甲型 $\mathrm{H}_{1} \mathrm{~N}_{1}$ 流感病毒抑制活性最高(Scheme 12). 


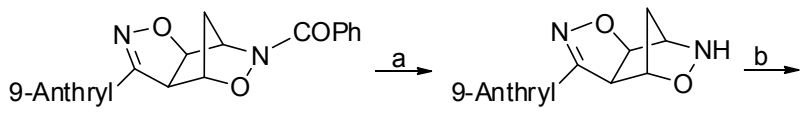

69
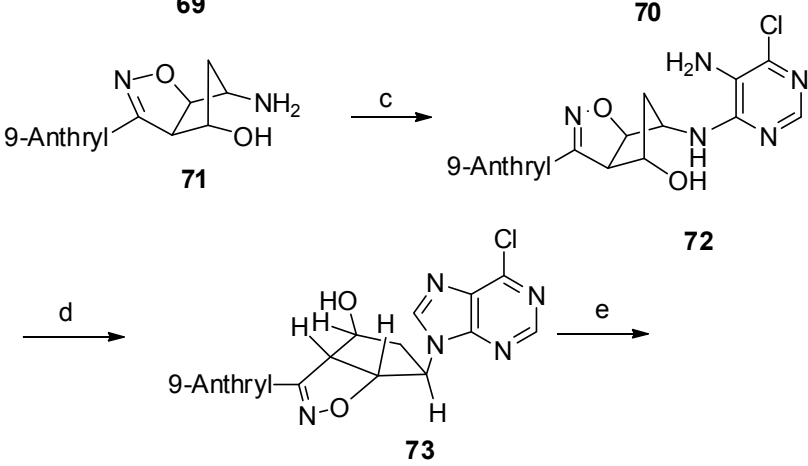

72

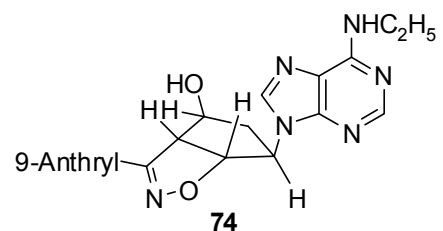

Reagents and conditions: (a) $\mathrm{NaOH} / \mathrm{MeOH}$, r.t., 12 h; (b) $\mathrm{H}_{2}, \mathrm{Pd} / \mathrm{C}$ $10 \%$, AcOEt, r.t., 3 h; (c) 5-amino-4,6-dichloropyrimidine, (2 equiv.), $i$-PrEtN (5 equiv.), $n$-ButOH, $\Delta, 48$ h; (d) $\mathrm{CH}(\mathrm{OEt})_{3}, p-\mathrm{TsOH}$, r.t., $6 \mathrm{~d}$; (e) $\mathrm{EtNH}_{2}, \mathrm{MeOH}, 50^{\circ} \mathrm{C}$.

\section{Scheme 11}

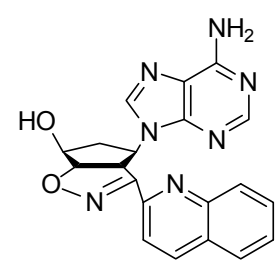

$75 a$<smiles>Nc1ncnc2c1ncn2C1CC(c2ccc3ccccc3n2)=NOC1O</smiles>

$75 b$

\section{Scheme 12}

除了前面提到的 $D$ 构型碳环核苷外，一些 $L$ 构型碳 环核苷同样具有抗病毒和抗肿瘤活性. Tanase 等 $^{[39]}$ 成功 合成了糖基部分为双环庚烷, 碱基为腺嘌呤和 6-取代腺 嘌呤的 $L$ 构型碳环核苷类似物 76a 761. 该 $L$ 构型碳环 核苷在全美国国立癌症研究所 60 人的肿瘤细胞检测中 显示出较低的抗癌活性, 但其中化合物 $76 \mathrm{~g}$ 对 SK-MEL-5 黑色素瘤和 UO-31 肾癌肿瘤细胞显示了最高 的活性. 他们从光学活性的双环庚烷化合物开始合成胺 类化合物，之后用于构建关键中间体 6-氯嘌呤的五元 环, 接着和氨及胺反应从而得到这些新型 $L$ 构型碳环核 苷类似物 76a 761 (Scheme 13).

\section{2 修饰的嘌呤碳环核苷}

修饰的嘌呤碳环核苷是指核苷的碱基部分为经过 改造的嘌呤环, 包括 1-脱氮嘌呤、3-脱氮嘌呤、7-脱氮 嘌呤和 8-氮杂嘌呤等.

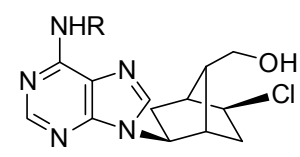

$76 a, 76 d \sim 76 \mathrm{I}$

$76 \mathrm{a} \mathrm{R}=\mathrm{H}$

76d $\mathrm{R}=\longrightarrow$<smiles>[Te][R6]=CC1CCCC1</smiles><smiles>[Te][Te]=C=CC1CCCCC1</smiles>

$76 \mathrm{~g} \mathrm{R}=ح \mathrm{C}_{6} \mathrm{H}_{5}$

76h $\mathrm{R}={ }_{\mathrm{NEt}_{2}}$

$76 \mathrm{i}=\mathrm{NEt}_{2}$

76j $\mathrm{NHR}=\mathrm{N} \mathrm{N}-\mathrm{CH}_{3}$

$76 \mathrm{NHR}=\mathrm{N}$

$76 \mathrm{kHR}=\mathrm{CH}_{\mathrm{NH}}^{\mathrm{NH}}$

Scheme 13

\subsection{1五元碳环核苷}

研究发现, 以 3-脱氮嘌呤 (1H-咪唑并 $[4,5$-c ]吡啶)为 框架的核苷类似物在抗病毒剂和生化研究的设计中有 重要用途 ${ }^{[40]}$. 在 3-脱氮嘌呤碳环类似物中, 3-脱氮 Aristeromycin ${ }^{[41]}$ 和 3-脱氮 Neplanocin $\mathrm{A}^{[42]}$ 是 $\mathrm{S}$-腺苷高半 胱氨酸水解酶的有效抑制剂, 显示出对 DNA 和 RNA 病 毒的抗病毒活性. 为了进一步探索 3-脱氮核苷, Jha 等 ${ }^{[43]}$ 合成了新型碳环核苷 3-脱氮 Carbovir (83)及其腺苷类似 物 79 和 81 . 该腺苷类似物合成的一大亮点是采用 6- $N, N$-二叔丁基氧羰基保护的 3-脱氮嘌呤 78 和 80 进行 区域选择性 Mitsunobu 偶联以及钯催化偶联. 6- $N, N-$ 二 苯基氨基保护的 3-脱氮鸟嘌呤碱基 82 与二碳酸酯进行 区域选择性钯催化偶联得到 3-脱氮 Carbovir (83). 所有 的目标核苷进行了抗 HIV-1 活性篎选，结果表明，他们 都没有显著活性并且毒性很高(Scheme 14).

在抗 $\mathrm{HCV}$ 病毒的研究中, 发现一些 7-脱氮嘌呤核 苷具有一定的抗 HCV 活性 ${ }^{[44]}$. Thiyagarajan 等 ${ }^{[45]}$ 运用以 结构为基础的方法设计并合理选择用于抗 $\mathrm{HCV}$ 活性评 价的分子, 在合成的 7-脱氮嘌呤碳环核苷中, $87 \mathrm{a} \sim 87 \mathrm{c}$ 具有抗 HCV 活性，其中化合物 87d 是该系列中最活跃 的, 但它也表现出一定的细胞毒性. 以市售的 4-氯-7H吡咯并 $[2,3-d]$ 嘧啶 (84)为原料，在三甲基铝和四(三苯基 膦)钯的催化作用下发生交叉偶联反应，接着在相应的 $N$-卤代琥珀酰亚胺的 DMF 溶液中, 氯/溴/碘成功引入到 


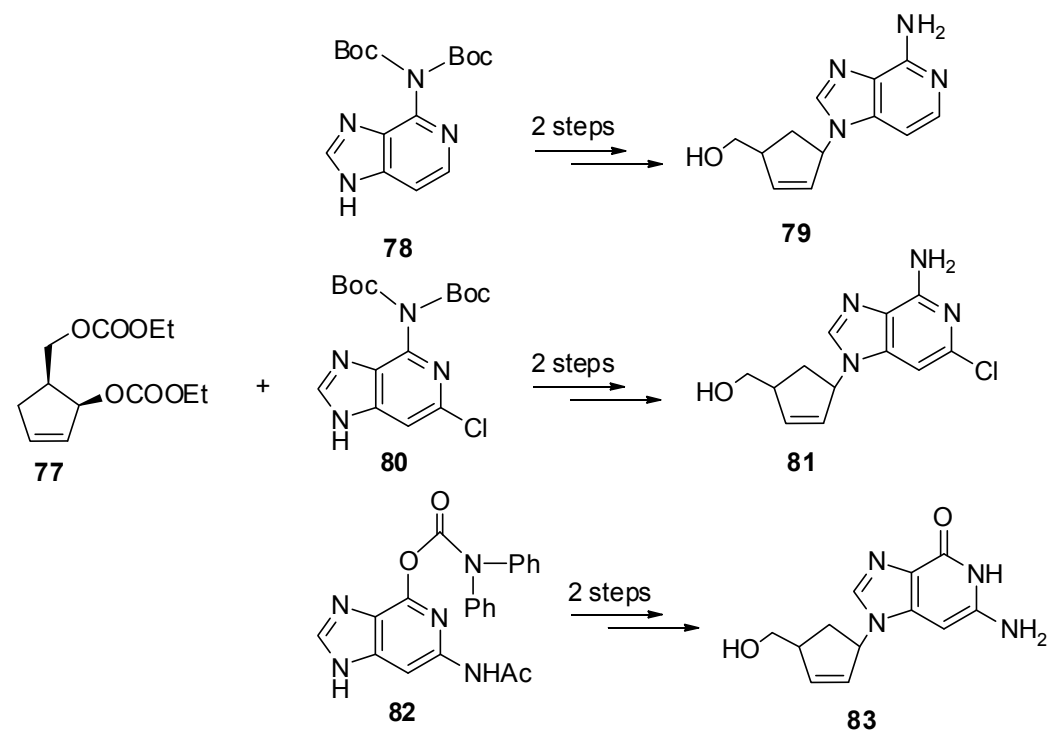

Scheme 14

4-甲基-7H-吡咯并[2,3- $d$ 嘧啶的 7-C 位置上, 生成产物 $85 \mathrm{a} \sim 85 \mathrm{c}$. 化合物 85a $\sim 85 \mathrm{c}$ 与改性的碳环糖 86 (由 $D$ 核糖(7)经过 8 步反应合成 ${ }^{[46]}$ )发生 Mitsunobu 偶合反应 得到 $85 \mathrm{a} \sim 85 \mathrm{c}$ 的保护的偶合产物, 经过分离, 纯化和脱 保护, 得到所需的最终化合物 87a $~ 87 \mathrm{c}$. 化合物 $87 \mathrm{c}$ 和 三丁基乙烯基锡进行反应引入乙烯基得到产物 $87 \mathrm{~d}$ (Scheme 15).

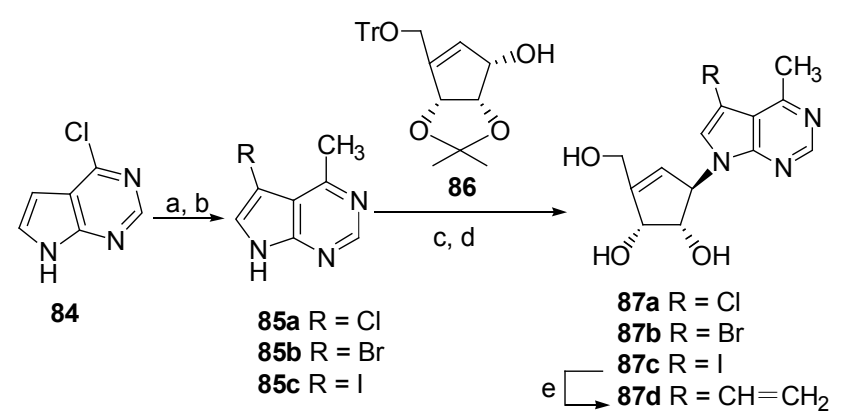

Reagents and conditions: (a) $\mathrm{Pd}\left(\mathrm{PPh}_{3}\right)_{4}, \mathrm{Al}\left(\mathrm{CH}_{3}\right)_{3}, \mathrm{THF}, 75^{\circ} \mathrm{C}, 8 \mathrm{~h}$; (b) Nhalosuccinimide, DMF, r.t., 10 h; (c) $\mathrm{Ph}_{3} \mathrm{P}, \mathrm{DIAD}$, THF, $0 \sim 5$ ${ }^{\circ} \mathrm{C}, 2 \mathrm{~h}$; (d) $10 \% \mathrm{HCl}$ in $\mathrm{CH}_{3} \mathrm{OH}, 60{ }^{\circ} \mathrm{C}, 5 \mathrm{~h}$; (e) $\mathrm{Pd}\left(\mathrm{PPh}_{3}\right)_{4}, \mathrm{Cul}$, tributylvinyltin, $\mathrm{Et}_{3} \mathrm{~N}, \mathrm{DMF}, 50^{\circ} \mathrm{C}, 6 \mathrm{~h}$

\section{Scheme 15}

\subsection{2 其他碳环核苷}

除了 3-脱氮嘌呤和 7-脱氮嘌呤碳环核苷, 研究发 现, 8-氮杂嘌呤碳环核苷也具有一定的抗病毒活性. Ugliarolo 等 ${ }^{[47]}$ 应用线性合成法以市售的 $(1 R, 2 R)$-反式- 1 -氨 基-2-狮满醇 $(\mathbf{8 8})$ 与 $(1 S, 2 S)$ - 反式-1-氨基-2-狮满醇 $(\mathbf{8 9})$ 为 原料合成了基于苑醇的新的手性嘌呤基和 8 -氮杂嘌呤 碳环核苷衍生物. 其中化合物 91 和 93 是迄今为止少有 的具有生物活性的 $\alpha$ 异构体碳环核苷. 通过评价这些核 苷衍生物的抗病毒活性表明, 反式-6-氨基-8-氮杂嘌呤
衍生物 90, 91 和顺式-6-氨基-8-氮杂嘌呤衍生物 92 在 HepG22.2.15 细胞中对 HBsAg 水平降低的百分比类似; 化合物 92 表现出对牛病毒性腹泻病毒(BVDV)的中度抑 制作用; 化合物 93 可作为开发新的细胞毒性药物的先 导化合物(Scheme 16).<smiles>N[C@H]1c2ccccc2C[C@H]1O</smiles>

88<smiles>NC1c2ccccc2C[C@H]1O</smiles>

89<smiles>Nc1ncnc2c1nnn2[C@@H]1c2ccccc2C[C@H]1O</smiles><smiles>Nc1ncnc2c1nnn2[C@@H]1c2ccccc2C[C@H]1O</smiles><smiles>Nc1ncnc2c1nnn2[C@@H]1c2ccccc2CC1O</smiles><smiles>O=C1C[C@H](O)[C@H](n2cnc3c(Cl)ncnc32)c2ccccc21</smiles>

93

Scheme 16

\section{2 嘧啶碳环核苷}

碳环核苷中碱基部分是嘧啶(尿嘧啶、胞嘧啶、胸 腺嘧啶)的核苷虽然不如碱基部分为嘌呤的核甘苷研究和 报道多，但仍引起各国药物研究人员对其合成研究的关 注. 下面将近 5 年来嘧啶碳环核苷按照碱基部分为尿嘧 啶、胞嘧啶、胸腺嘧啶分别进行简要综述.

\section{1 尿嘧啶碳环核甘}

最近, Matyugina 等 ${ }^{[48]}$ 合成和评价了一系列新的碳 环尿嘧啶衍生物, 可视为潜在的抗结核试剂. 消旋的 
1-[4'-差基-2'-环戊烯-10-基]-5-四癸炔基尿嘧啶完全抑制 了结核分枝杆菌 $\mathrm{H} 37 \mathrm{Rv}$ 在体外的增殖. 合成的新的尿 嘧啶衍生物对两株结核分枝杆菌显示出相同水平的活 性，它们分别为实验室敏感型(结核分枝杆菌 H37Rv)和 临床耐五大抗结核药物型(MS-115). 环氧环戊烯与 5-碘 尿嘧啶经过 Trost 步骤[49]发生偶合反应得到化合物 95. 1-(4'-乙酰氧基-2'-环戊烯-1'-基)-5-碘尿嘧啶 [(+)-96]和 碳酸钾的甲醇溶液反应得到 $(+)-1-\left(4^{\prime}\right.$-羊基-2'-环戊 烯-1'-基)-5-碘尿嘧啶 [(+)-95]. 化合物(+)-96 和(-)-95 分别转化成相应的 5-四癸基-尿嘧啶衍生物 $(+)-97$ 和 (-)-97. 目标化合物 $(+)-97$ 和(-)-97 的绝对构型可通 过旋光度 $[\alpha]_{\mathrm{D}}$ 值和圆的二色性数据确定 (Scheme 17).
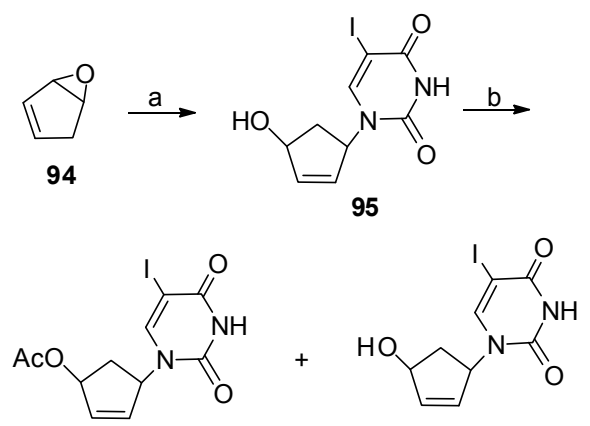

$(+)-96$

$(-)-95$

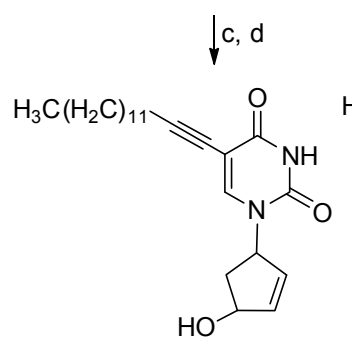

$(+)-97$

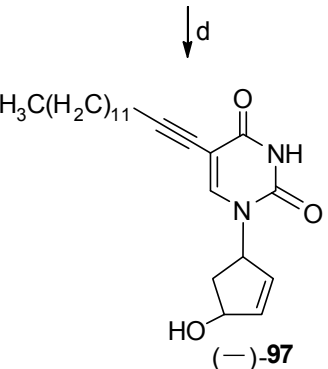

$(-)-97$

Reagents and conditions: (a) 5-iodouracil, $\mathrm{Pd}\left(\mathrm{PPh}_{3}\right)_{4}, \mathrm{THF} / \mathrm{DMF}$; (b) Amano PS lipase, vinyl acetate; (c) $\mathrm{K}_{2} \mathrm{CO}_{3}, \mathrm{CH}_{3} \mathrm{OH}$; (d) $\mathrm{HC} \equiv \mathrm{CC}_{12} \mathrm{H}_{25}$, Cul, NEt(i-Pr) $)_{2}, \operatorname{Pd}\left(\mathrm{PPh}_{3}\right)_{4}$, DMF.

\section{Scheme 17}

此外, Cesario 等 ${ }^{[00]}$ 在 2009 年合成了碳环尿嘧啶多 氧菌素类似物 98a, 98b 和 99a, 99b. 他们以一个酰基亚 硝基衍生的杂 Diels-Alder 环加成物开始用不到九步反 应合成. 其中得到 $98 \mathbf{a}$ 和 $98 \mathrm{~b}$ 的比例为 $1: 3$, 为了进一 步提高 98a 的比例, 采用 Woodward-Prevost 条件引入顺 式一二醇. 目前对于化合物 98a, 98b, 99a 及 99b 的抗癌、 抗微生物、抗病毒和抗真菌活性正在进一步检测中 (Scheme 18).

\section{2 胞嘧啶碳环核甘}

在嘌呤碳环核苷的合成部分中曾提到，在碳环糖基 引入氟原子可产生有效的抗病毒剂 ${ }^{[28]}$. 其中 $2^{\prime}$-氟-6'-亚 甲基碳环腺苷(FMCA, 55)显示出显著的抗 HBV 活性.

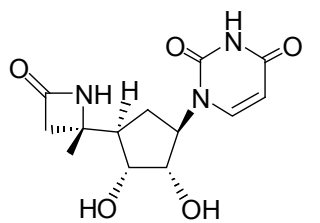

$( \pm)-98 a$

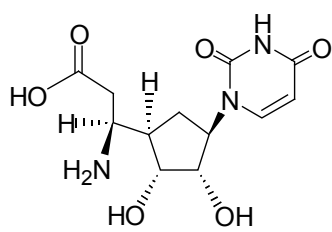

$( \pm)-99 a$

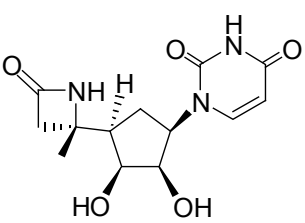

$( \pm)-98 b$

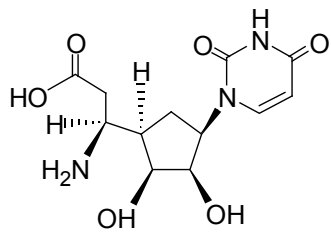

$( \pm)-99 b$

\section{Scheme 18}

Kim 及 Lee 等 ${ }^{[11]}$ 设计了碳环核苷的氟化类似物作为抗 $\mathrm{HCV}$ 试剂, 专注于 $2^{\prime}(\beta)$-C 甲基碳环核苷的 2'-位的修饰. $2^{\prime}$-位上的双取代可能施加有利的空间位阻并与 HCV 聚 合酶产生相互作用的电子效应.

他们应用新颖的有效合成路线合成 $2^{\prime}(\alpha)-\mathrm{C}$-氟代$2^{\prime}(\beta)$-C-甲基碳环核苷类似物。关键的氟化中间体 102 通过选择性环氧化物开环反应制备, 原料为环氧化物中 间体 100. 化合物 102 和核苷碱基通过 Mitsunobu 反应 进行偶合，去保护得到目标核苷类似物. 对合成的化合 物 105 进行评价, 结果表明其作为丙型肝炎病毒 $(\mathrm{HCV})$ 抑制剂，微弱抑制复制子 NK-R2AN 的复制(Scheme 19).

在 2010 年, Jonckers 等 ${ }^{[52]}$ 报道了 $2^{\prime}$-螺环丙基-核糖 胞嘧啶核苷的合成，其通过一种参与丙型肝炎病毒 $(\mathrm{HCV})$ 编码的 RNA 聚合酶 NS5B，强效抑制了 RNA 的 合成. 基于他们的启发, $\mathrm{Li}$ 等 ${ }^{[53]}$ 在 2011 年合成了几种 2'螺环丙基-碳环核苷并进行生物活性评价. 结果表明, 合成的核苷类似物在亚基因组复制子的 Huh7 细胞系中 具有抑制 HCV 的 RNA 复制的能力. 其中, 胞嘧啶核苷 类似物 116 表现出显著的抗 $\mathrm{HCV}$ 活性. 该环戊烯醇中 间体 108 由二乙烯基 107 通过闭环复分解( $\mathrm{RCM}$ )顺利合 成. 通过使用(2-氯乙基)二甲基锍碘化物和叔丁醇钾烯 酮 109 发生螺环丙基化得到所需的中间体 110 (Scheme $20)$.

碳环核苷类似物之所以被广泛关注是因为其抗病 毒和抗肿瘤活性，除此之外，放射性标记的碳环核苗还 用于评估单纯疮疹病毒 1 型胸苷激酶(HSV1-tk)成像. HSV1-tk 被广泛用于研究基因表达 ${ }^{[54]}$. 各种放射性标记 的核苷类似物，包括嘧啶和无环鸟甘衍生物已被合成并 用于评估 HSV1-tk 成像 ${ }^{[55]} .2007$ 年, Ahn 等 ${ }^{[56]}$ 合成了放 射性碘标记的尿嘧啶碳环核苷, 并进行生物学评价. 发 


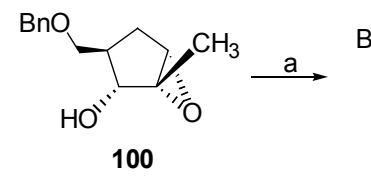<smiles>CC1CC[C@H](CBr)[C@@H](Br)[C@H]1O</smiles>

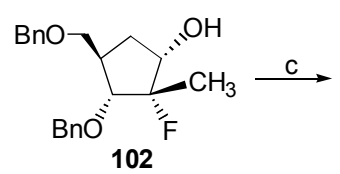
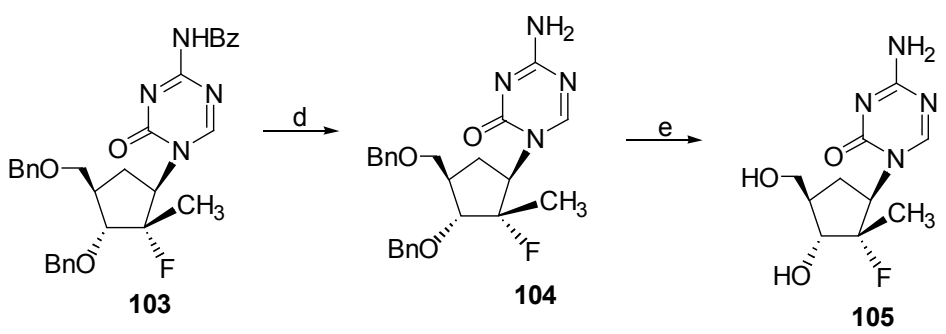

Reagents and conditions: (a) BnBr, NaH, DMF; (b) 47\% HF, $\left(\mathrm{NH}_{4}\right)_{2} \mathrm{SiF}_{6}$, CsF; (c) $\mathrm{N}_{4}$-Bz-cytosine, $\mathrm{PPh}_{3}, \mathrm{DIAD}$; (d) $\mathrm{NaOMe} / \mathrm{MeOH}$; (e) Pa(OH) cyclohexene, $\mathrm{MeOH}$, reflux.

Scheme 19

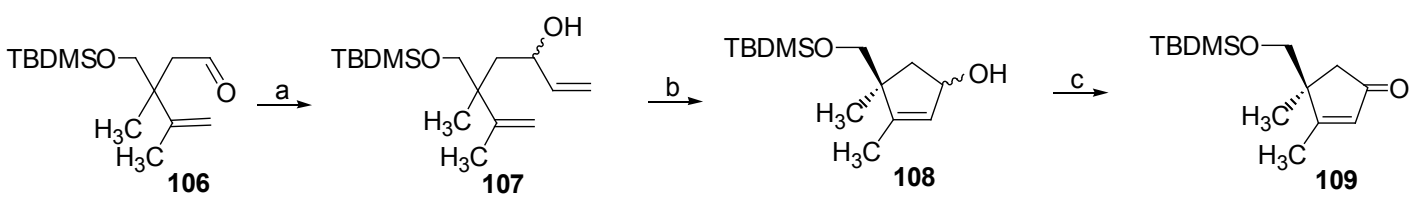
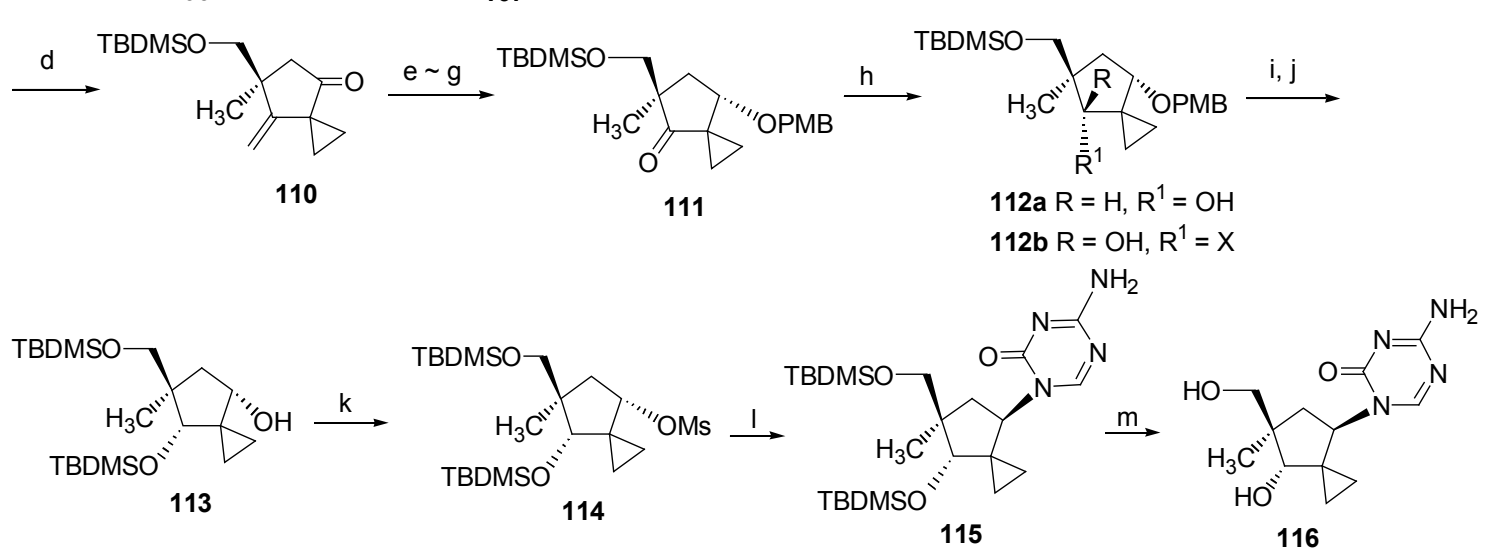

Reagents and conditions: (a) vinylMgBr, $-20{ }^{\circ} \mathrm{C}$, THF; (b) Grubbs catalyst(II), benzene; (c) $\mathrm{MnO}_{2}, \mathrm{CCl}_{4}$; (d) $\mathrm{ClCH}_{2} \mathrm{CH}_{2} \mathrm{SMe}_{2} \mathrm{l}, \mathrm{KI}, t$-BuOK, $t$-BuOH; (e) $\mathrm{LiAlH}_{4}$, ether; (f) PMBCl, NaH, DMF; (g) $\mathrm{O}_{3}, \mathrm{DMS}, \mathrm{CH}_{2} \mathrm{Cl}_{2}$; (h) $\mathrm{LiAlH}_{4}$, ether; (i) TBDMSCl, imidazole, $\mathrm{CH}_{2} \mathrm{Cl}_{2} ;(\mathrm{j}) \mathrm{DDQ}, \mathrm{CH}_{2} \mathrm{Cl}_{2}$, $\mathrm{H}_{2} \mathrm{O}$; (k) MsCl, TEA, $\mathrm{CH}_{2} \mathrm{Cl}_{2}$; (l) bases, $\mathrm{NaH}$, DMF; (m) TBAF, THF/CH $\mathrm{CH}_{3} \mathrm{CN}$

\section{Scheme 20}

现它们是单纯疮疹病毒 1 型胸苷激酶(HSV1-tk) 有力的 成像材料. 2011 年, 他们又成功合成了放射性标记顺 式-1-[4-(差基-甲基)-环戊-2-烯基]-5-[ $\left.{ }^{124} \mathrm{I}\right]$-碘胞嘧啶(碳 环 d4IC) 及顺式-1-[4-(羟基-甲基)-环戊-2-烯基]-

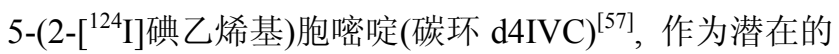
HSV1-tk 成像探头.

其中关键反应为钯 $(0)$ 催化的偶联反应及有机锡和 碘标记的交换反应. 得到的碳环 $\left.{ }^{124} \mathrm{I}\right] \mathrm{d} 4 \mathrm{IC}$ 的放射化学 产率超过 75\%, 放射化学纯度大于 $95 \%$. 碳环 $\left[{ }^{124} \mathrm{I}\right]$ d 4 IVC 的放射化学产率为 $80 \%$ 以上, 放射化学纯度大于 95\%. 以化合物 117 为原料, 117 可由环戊二烯和乙醛酸 经过四步反应合成 ${ }^{[58]}$. 化合物 117 和 5-碘胞嘧啶(118) 在钯 $(0)$ 催化条件下发生 Tsuji-Trost 交叉偶联反应得到 化合物 119. 化合物 119 在钯 $(0)$ 催化条件下经过双(三丁
基锡)浓缩转化为锡化前体 $\mathbf{1 2 0}$. 化合物 $\mathbf{1 2 0}$ 发生放射性 碘化作用得到标记的化合物 121. 化合物 121 用 0.5 $\mathrm{mol} \cdot \mathrm{L}^{-1}$ 的碳酸钾进行水解, 然后将碳环 $\mathrm{d} 4 \mathrm{IC}(\mathbf{1 2 2})$ 进行 分离，收集，并且使用反相高效液相色谱-紫外和放射 性探测器进行分析. 化合物 119 发生钯(0)催化的 Stille 偶联反应转化成一个三甲基硅基乙烯基化合物 123, 经 水解得到化合物 124. 同得到化合物 122 的方法一样, 最后得到碳环 d4IVC (125) (Scheme 21).

\section{3 胸腺嘧啶碳环核苷}

新的抗疮疾药物中, 恶性疮原虫胸苷酸激酶 (PfTMK) 因为其独特的底物特异性作为重要的药物靶 标. 与人类胸苷激酶(HsTMK)相比, $P f \mathrm{TMK}$ 显示更广泛 的底物特异性, 其中包括嘌呤和嘧啶核苷酸. PfTMK 同 


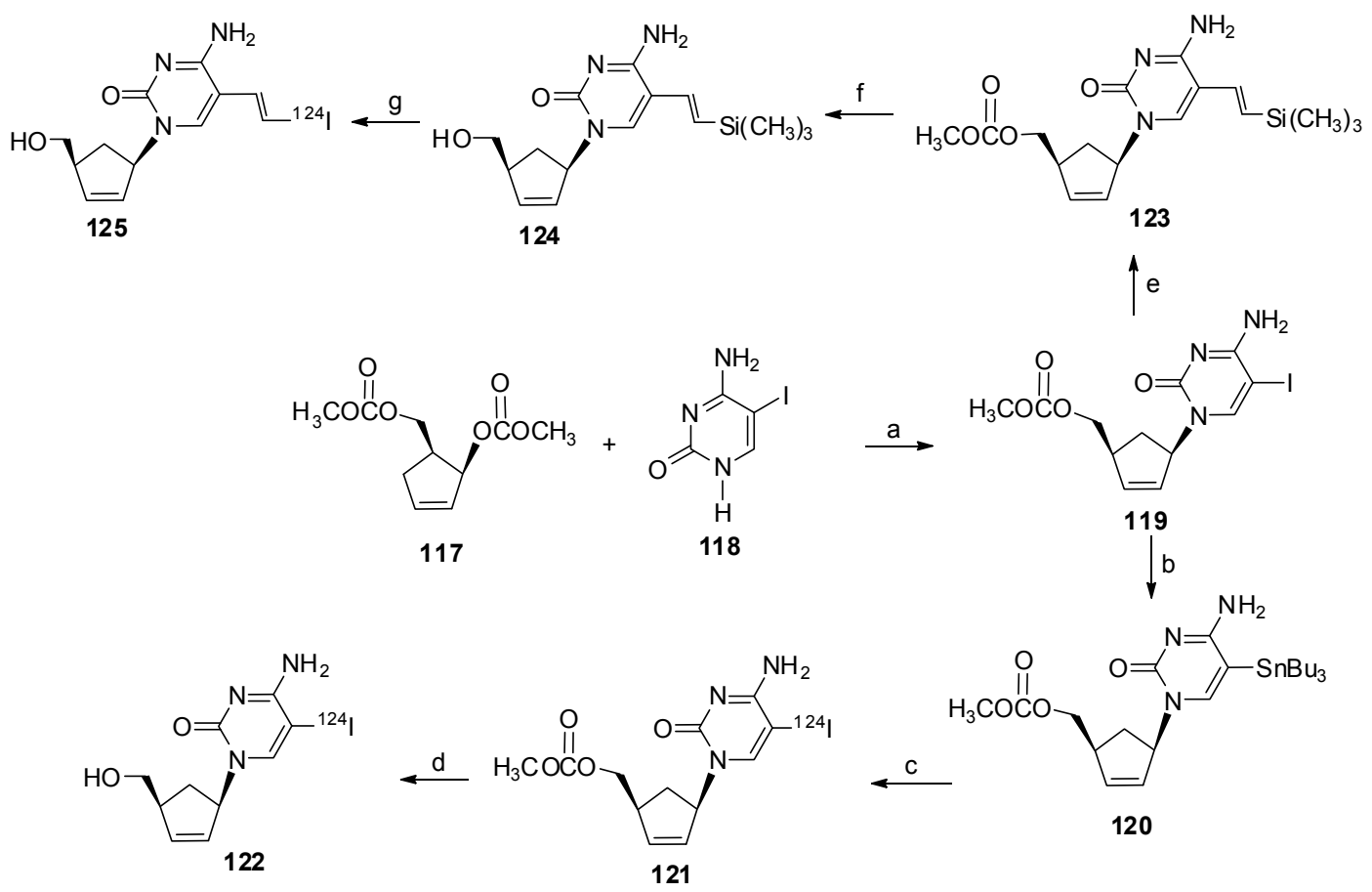

Reagents and conditions: (a) (i) $\mathrm{Pd}(\mathrm{OAc})_{2}$, (i-PrO) $)_{3} \mathrm{P}$, THF, under argon, r.t.; (ii) $n$-BuLi, hexane, r.t.; (iii) 118 and $\mathrm{NaH}$ in DMSO; (iv) 117 in

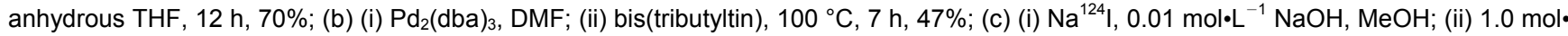
$\mathrm{L}^{-1} \mathrm{HCl}$ to $\mathrm{pH} 4.0,30 \% \mathrm{H}_{2} \mathrm{O}_{2}, 10 \mathrm{~min}$; (iii) $\mathrm{NaHSO}_{3}$; (d) (i) $1.0 \mathrm{~mol} \cdot \mathrm{L}^{-1} \mathrm{~K}_{2} \mathrm{CO}_{3}$, r.t., $1 \mathrm{~h}$; (ii) $1.0 \mathrm{~mol} \cdot \mathrm{L}^{-1} \mathrm{HCl}$ to $\mathrm{pH} 7$; (e) $(E)-\mathrm{Bu}_{3} \mathrm{SnCH}=\mathrm{CHSiMe}_{3}$, $\mathrm{Pd}_{2}(\mathrm{dba})_{3}, \mathrm{DMF}, 12 \mathrm{~h}, 60{ }^{\circ} \mathrm{C}, 60 \%$; (f) (i) $0.5 \mathrm{~mol} \cdot \mathrm{L}^{-1}$ aqueous $\mathrm{K}_{2} \mathrm{CO}_{3}$, r.t., $12 \mathrm{~h}$; (ii) $1.0 \mathrm{~mol} \cdot \mathrm{L}^{-1} \mathrm{HCl}, 93 \%$; (g) (i) $\mathrm{Na}{ }^{124} \mathrm{I}, 0.01 \mathrm{~mol} \cdot \mathrm{L}^{-1} \mathrm{NaOH}$, $\mathrm{MeOH}$; (ii) $1.0 \mathrm{~mol} \cdot \mathrm{L}^{-1} \mathrm{HCl}$ to $\mathrm{pH} 4.0,30 \% \mathrm{H}_{2} \mathrm{O}_{2}, 10 \mathrm{~min}$; (iii) $\mathrm{NaHSO}_{3}$

\section{Scheme 21}

时接受 $2^{\prime}$-脱氧鸟苷一磷酸(dGMP)和胸苷一磷酸(TMP) 作为底物. Yasuda 等 ${ }^{[59]}$ 评估了七个碳环胸腺嘧啶核苷类 似物对 PfTMK 的抑制活性，并报道了这些抑制剂对 PfTMK 的第一构效关系. $2^{\prime}, 3^{\prime}$ 胸腺嘧啶二脱氧碳环核苷 衍生物显示出对酶最有效的抑制作用. 所有的化合物均 为外消旋体. 3,5-二乙酰环戊烯依照文献的步骤制备, (土)-126 的制备根据文献报道的方法 ${ }^{[60]}$ (Scheme 22). $( \pm)-126$ 与钯四三苯基膦和胸腺嘧啶在 $\mathrm{NaH}$ 存在下得到 碳环核苷 $( \pm)-127$. 接着进行脱乙酰化, 得到关键化合 物(土)-128. 然后进行烯烃双羟基化得到低选择性混合 物二醇 ( \pm )-129 和 $( \pm)-130(3: 2)$. 烯类似物 $( \pm)-128$ 加 氢得到相应的 $2^{\prime}, 3^{\prime}$-二脱氧碳环核苷 $( \pm)-131$. 化合物 $( \pm)-128$ 和 $m$-CPBA 在 THF 中反应得到立体选择性的环 氧化物 $( \pm)-132.2^{\prime}-$ 脱氧类似物 $( \pm)-133$ 由 $( \pm)-129$ 通过 选择性保护 $3^{\prime}$-和 5'-羟基基团以及 2'-硫代碳酸酯还原得 到.

在之前工作的基础上, Yasuda 等 ${ }^{[61]}$ 于 2013 年还设 计并合成了对映选择性 $2^{\prime}, 3^{\prime}$-二脱氧碳环嘧啶核苷, 并 篮选了他们对 PfTMK 的抑制活性. 其中氟化二脱氧衍 生物(一)-137 对 PfTMK 表现出较强的抑制活性. 碳环的 嘧啶衍生物的合成如 Scheme 23 所示. 所有化合物均得 到单一对映体. 四(三苯膦)合钯 [钯四三苯基膦]是碳三
醋酸(一)-134 的烯丙基酯与 3-苯甲酰胸腺嘧啶耦合的 催化剂, 得到结构保留的碳环嘧啶衍生物(一)-135. 随 后用氨的甲醇溶液脱保护基得到(-)-136. 化合物 (一)-136 在 $N, N$-二乙胺基三氟化硫(DAST)条件下, 其 端羟基被置换为氟原子, 得到一氟化物 ( - )-137 (Scheme 23).

\section{3 碳环 C-核苷}

碳环 $\mathrm{C}$-核苷 ${ }^{[62]}$ 是指一些碳环假糖与杂环碱基通过 碳一碳键连接的衍生物, 其在生物医学应用领域的发展 中属于非常重要的概念. 第一次尝试合成碳环 $C$-核苷 可以追溯到 20 世纪 60 年代 ${ }^{[63]}$, 但从那以后仅有几个这 类化合物的合成和生物活性测试的报道. Rao 等 ${ }^{[64]}$ 发现 9-脱氮杂 Neplanocin A 具有适度抗 HIV 活性, 并发现几 个嘧啶碱基环戊烯基类似物的碳环 $C$-核苷具有抗病毒 活性. 近几年来, 碳环 $C$-核苷的生物活性引起药物化学 家们的广泛关注 ${ }^{[65]}$.

在 2010年, Hřebabecký 等 ${ }^{[66]}$ 提出了两种构建新型碳 环 $C$-核苷的汇聚(Convergent)合成方法. 合成了 5-C 以 及 6-C 取代的尿嘧啶杂环碱基衍生物. 第一种方法的关 键步骤是核苷碱基前体(6-氯-2,4-二甲氧基嘧啶-5-基)锂 与碳环假糖前体酮的反应. 第二种方法是基于铜催化 


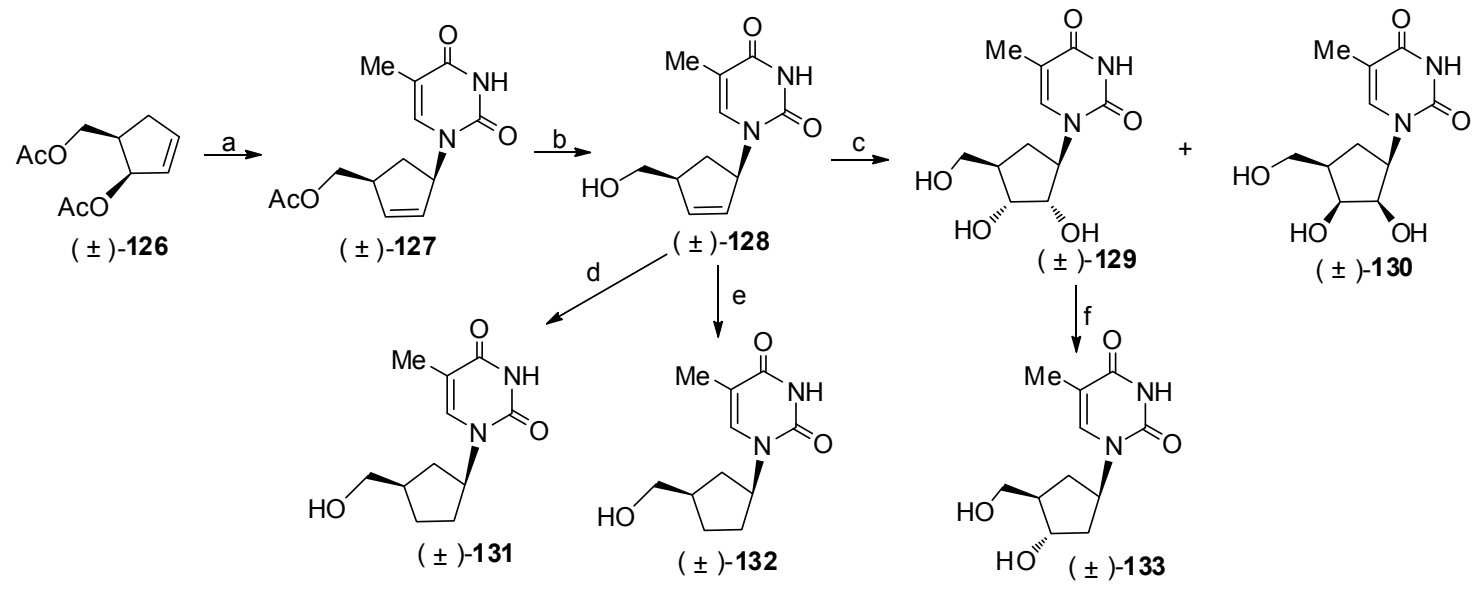

Reagents and conditions: (a) $\mathrm{Pd}\left(\mathrm{PPh}_{3}\right)_{4}, \mathrm{PPh}_{3}, \mathrm{NaH}$, THF, DMSO, $60{ }^{\circ} \mathrm{C}, 74 \%$; (b) $\mathrm{MeONa}, \mathrm{MeOH}$, r.t., $96 \%$; (c) OsO $\mathrm{O}_{4}, \mathrm{NMO}, \mathrm{THF}, \mathrm{H}_{2} \mathrm{O}$, r.t., ( \pm )-129 59\%, ( \pm )-130 39\%; (d) $\mathrm{H}_{2}, \mathrm{Pd} / \mathrm{C}, \mathrm{AcOH}, \mathrm{MeOH}$, rt, 93\%; (e) $\mathrm{m}$-CPBA, THF, r.t., quant; (f) (i) $\mathrm{TIPDSCl}$, imidazole, DMF, r.t., 56\%; (ii) $\mathrm{PhOC}(\mathrm{S}) \mathrm{Cl}$, DMAP, pyridine, r.t., $90 \%$; (iii) $\mathrm{Bu}_{3} \mathrm{SnH}$, AIBN, $80^{\circ} \mathrm{C}, 60 \%$; (iv) TBAF, THF, r.t., $96 \%$

Scheme 22

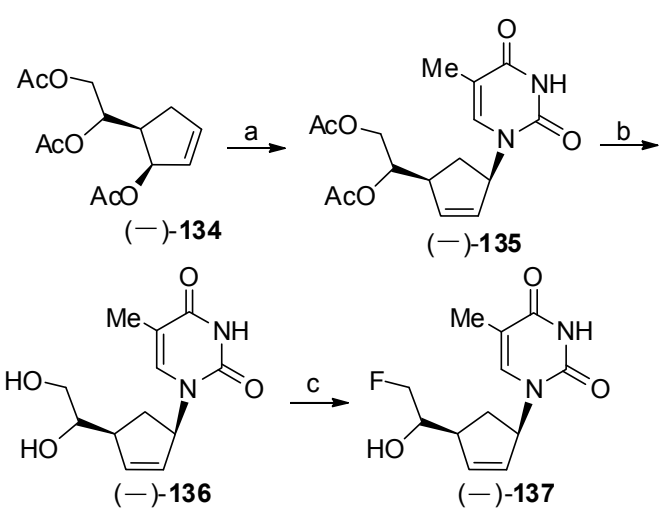

Reagents and conditions: (a) $\mathrm{Pd}\left(\mathrm{PPh}_{3}\right)_{4}, \mathrm{PPh}_{3}, \mathrm{NaH}, \mathrm{THF}, \mathrm{DMSO}$, $60{ }^{\circ} \mathrm{C}$; (b) $\mathrm{NH}_{3} / \mathrm{MeOH}, 120^{\circ} \mathrm{C}$; (c) DAST, $\mathrm{CH}_{2} \mathrm{Cl}_{2}, 0^{\circ} \mathrm{C}$

\section{Scheme 23}

的交叉偶合反应，反应物为镁化的嘧啶和烯丙基氯. 这 些方法已用于合成以环已烯或环已烷作为假糖的新型 碳环 C-核苷.

在第一种方法中, 以环已-3-烯-1,1-二甲醇(138)为 原料, 化合物 138 经过三苯甲基化和随后的环氧化得到 化合物 139. 环已醇 140 和 141 由环氧化物 139 与氢化 铝锂在乙醚中发生还原反应得到. 化合物 140 和 141 可 通过简单的色谱法进行分离. 进一步由重铬酸吡啶鎓 (PDC)在 $N, N$-二甲基甲酰胺中进行氧化成䣶 142 和 143 (Scheme 24).

该途径的关键步骤是酤 142 和 143 与 6-氯-2,4-二甲 氧基嘧啶-5-锂(145)的反应. 化合物 145 是由 6-氯-2,4二甲氧基嘧啶(144)和正丁基锂反应得到的. 酮 142 与有 机锂化合物 145 反应得到加合物, 反应温度保持在约一 $30{ }^{\circ} \mathrm{C}$ 时收率较高. 再经过脱保护基、消除叔羟基、催化 氢化反应得到假糖尿嘧啶衍生物 146 . 酩 143 进行类似 的操作, 经过脱保护/消除、氢化反应得到最终化合物

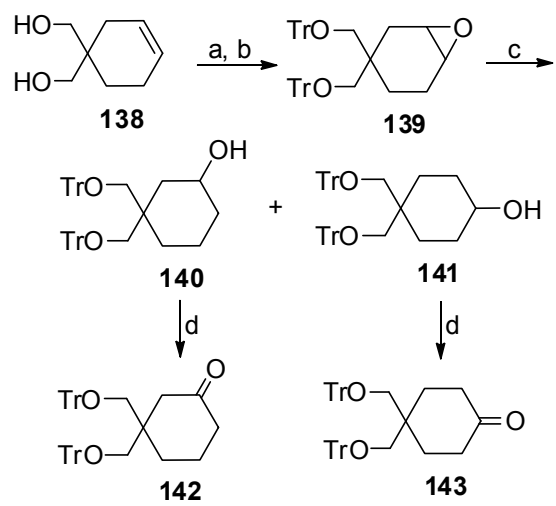

Reagents and conditions: (a) $\mathrm{TrCl}$, pyridine, $100{ }^{\circ} \mathrm{C}, 86 \%$; (b) MCPBA, $\mathrm{CH}_{2} \mathrm{Cl}_{2}, 0{ }^{\circ} \mathrm{C}, 75 \%$; (c) $\mathrm{LiAlH}_{4}, \mathrm{Et}_{2} \mathrm{O}, 40 \%$ of $140,37 \%$ of 141 ; (d) PDC, DMF, $88 \%$ of $142,86 \%$ of 143

Scheme 24

148. 另外, 化合物 147 经过两步消除反应得到最终产物 149 (Scheme 25).

在第二种方法中, 仍以化合物 138 为原料, 关键烯 丙基中间体 151 和 152 由环氧化物 150 制备. 化合物 138 经过甲酰化和环氧化得到化合物 150, 接着由路易 斯酸诱导重排以及三甲基甲硅烷基醚在稀盐酸条件下 水解得到化合物 151 和 152, 其可通过柱色谱法分离, 比例为 $1: 1$. 化合物 151 和 152 在复合三苯基膦- $N$-氯 代琥珀酰亚胺条件下转化为相应的烯丙酰氯 153 和 154 (Scheme 26).

起始嘧啶碘化物 4-碘-2,6-二甲氧基嘧啶(157)和 4碘-2,6-二甲氧基-5-甲基嘧啶(158)是由三氯嘧啶经过两 步反应得到的. 关键反应为烯丙基氯化物 153 和 154 分 别与镁化的嘧啶 157 (158)进行交叉偶合, 得到最终产物 159 (160)和 161 (162) (Scheme 27). 


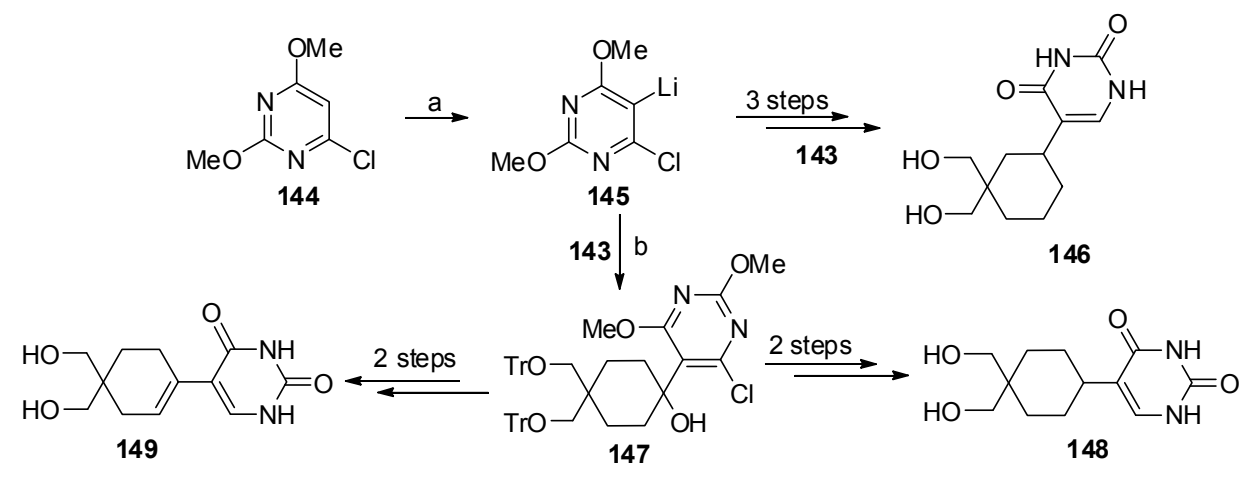

Reagents and conditions: (a) $n$-BuLi, THF, $-75^{\circ} \mathrm{C}$; (b) THF, $<-20^{\circ} \mathrm{C}, 89 \%$.

Scheme 25
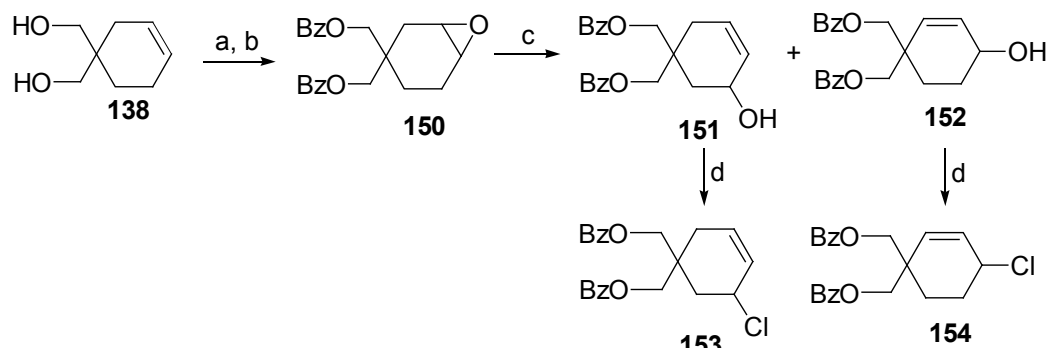

153

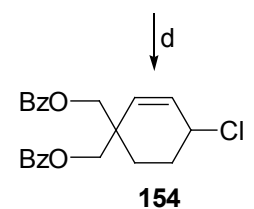

Reagents and conditions: (a) $\mathrm{BzCl}$, pyridine, $78 \%$; (b) MCPBA, $\mathrm{CH}_{2} \mathrm{Cl}_{2}, 77 \%$; (c) (i) TMSOTf, DBU, toluene; (ii) aq. $\mathrm{HCl}, \mathrm{MeOH}, 34 \%$ of 151 , $31 \%$ of 152 ; (d) NCS, $\mathrm{PPh}_{3}, \mathrm{THF}, 87 \%$ of $153,88 \%$ of 154

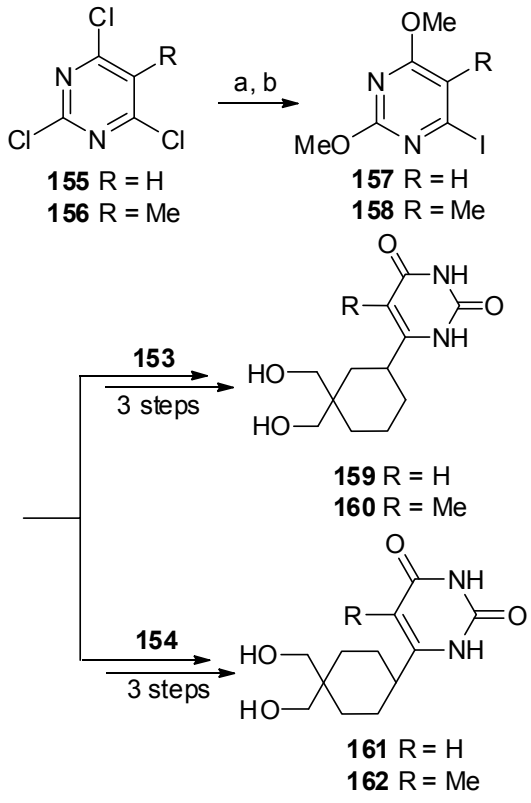

Reagents and conditions: (a) $57 \% \mathrm{HI}$; (b) $\mathrm{NaOMe}, \mathrm{MeOH}$, THF, $50 \%$ for 157 ( 2 steps, $11 \%$ of byproduct), $56 \%$ for 158 ( 2 steps)

\section{Scheme 27}

\section{4 结论和展望}

综上所述，自 1966 年首个天然碳环核苷类似物被 成功合成以来 ${ }^{[67]}$, 许多实验室都开展了这一类的合成 方法及生物活性谱研究，直到现在，这类化合物仍吸引

\section{Scheme 26}

大家的广泛关注. 这种兴趣可以归因于下述两个因素: (1)碳环类似物在结构上类似于天然核苷，这意味着碳 环核苷类似物与天然核苷可能具有相似的代谢活性. (2)碳环核苷类似物的糖环是高度稳定的，一方面为碳 环核苷类似物的合成提供了方便，另一方面也可能部分 解决当前核苷类药物的稳定性问题. 由于这些特性的组 合, 碳环类似物为细胞生化过程的基础研究提供了重要 工具. 碳环核苷类化合物的三名成员阿巴卡韦、洛布卡 韦和恩替卡韦被成功用作临床药物, 这清楚地表明研究 这些化合物的现实意义及应用价值.

总之, 以后对于碳环核苷类似物的研究将集中于以 下几个方面: (1)碳环核苷类似物的合成策略还有待开发 和研究. 在两种连接杂环碱基和碳环假糖的方法中, 会 聚(convergent) ${ }^{[68]}$ 合成法是最常用的方法，该方法基于 亲核取代/加成，包括直接亲核取代、钯催化烯丙基取代 以及共轭加成. 另一种线性(linear)合成策略虽由于结构 限制，应用较少，但是在某些碳环核苷的合成中，依然 是最为简便而经济的方法. 该方法的核心是由环戊胺构 造碱基. 这两种策略的选择与比较值得进一步研究. (2) 尽管对于特定化合物的作用靶点和生物活性机制已经 建立，但仍存在很多不同结构的碳环类似物有待发掘. 新型碳环核苷类似物的合成仍是未来研发的一个关键 问题. (3)对于已知的碳环核苷药物，如何从分子水平解 释其作用机制，以此为基础，利用计算机模拟的技术对 
于碳环核苷类似物进行分子设计以及生物活性与化学 结构之间关系研究, 最终为新化学实体提供指导性建 议, 也将是本领域的一项重要工作. (4)在对合成的碳环 核苷进行抗病毒活性的研究中, 由于进行抗病毒活性所 要求的实验室资质较高, 普通实验室无法进行抗病毒活 性研究, 这成为核苷类化合物抗病毒活性研究进展较慢 的一个瓶颈. 因此加强国内外合作, 提高国内实验室核 苷类药物研究条件, 将成为突破这一瓶颈的有效解决途 径, 应得到国家及药物研究工作者的大力提倡和支持.

\section{References}

[1] Jeong, L. S.; Lee, J. A. Antiviral Chem. Chemother. 2004, 15, 235.

[2] Matyugina, E. S.; Khandazhinskaya, A. L.; Kochetkov, S. N. Russ. Chem. Rev. 2012, 81, 729

[3] Montgomery, J. A. Med. Res. Rev. 1982, 2, 271.

[4] (a) Daluge, S. M.; Good, S. S.; Faletto, M. B. Antimicrob. Agents Chemother. 1997, 41, 1082.

(b) Innaimo, S. F.; Seifer, M.; Bisacchi, G. S.; Standring, D. N.; Zahler, R.; Colonno, R. J. Antimicrob. Agents Chemother. 1997, 41, 1444.

[5] Guo, X.-H.; Kang, H.; Zheng, L.-X.; Jiang, S.-D. Chin. J. Org. Chem. 2011, 31, 176 (in Chinese). (郭翔海, 康宏, 郑岗曦, 姜申德, 有机化学, 2011, 31, 176.)

[6] Boutureira, O.; Isabel, M. M.; Díaz, Y.; Castillón, S. Chem. Soc. Rev. 2013, 42, 5056.

[7] (a) Crimmins, M. T. Tetrahedron 1998, 54, 9229

(b) Zhu, X.-F. Nucleosides Nucleotides 2000, 19, 651.

(c) Douadi, A.; Brémond, P.; Lanez, T.; Pannecouque, C.; Audran, G. Synlett 2011, 111.

[8] Fan, X.-S.; Zhang, X.-Y.; Wang, X.; Qu, G.-R. Chin. J. Org. Chem. 2008, 28, 1888 (in Chinese) (范学森, 张新迎, 王霞, 渠桂荣, 有机化学, 2008, 28, 1888.)

[9] Kusuka, T.; Yamamoto, H.; Shibata, M.; Muroi, M.; Kishi, T.; Mizuno, K. J. Antibiot. 1968, 21, 255.

[10] Yaginuma, S.; Muto, N.; Tsujino, M.; Sudate, Y.; Hayashi, M.; Otani, M. J. Antibiot. 1981, 34, 359.

[11] (a) Vince, R.; Hua, M.; Brownell, J.; Daluge, S.; Lee, F.; Shannon, W. M.; Lavelle, G. C.; Qualls, J.; Weislow, O. S.; Kiser, R.; Canonico, P. G.; Schultz, R. H.; Narayanan, V. L.; Mayo, J. G.; Shoemaker, R. H.; Boyd, M. R. Biochem. Biophys. Res. Commun. 1988, 156, 1046.

(b) Vince, R.; Hua, M. J. Med. Chem. 1990, 33, 17.

[12] (a) Hayashi, M.; Yaginuma, S.; Muto, N.; Tsujino, M. Nucleic Acids Res. 1980, 8, 65.

(b) Comin, M. J.; Leitofuter, J.; Rodriguez, J. B. Tetrahedron 2002, $58,3129$.

[13] (a) Bodenteich, M.; Marquez, V. E.; Hallows, W. H.; Goldstein, B. M. J. Org. Chem. 1992, 57, 2071.

(b) Zhang, H.; Schinazi, R. F.; Chu, C. K. Bioorg. Med. Chem. 2006, 14, 8314.

[14] Kim, Y. A.; Rawal, R. K.; Yoo, J.; Sharon, A.; Jha, A. K.; Chu, C. K.; Rais, R. H.; Al Safarjalani, O. N.; Naguib, F. N.; El Kouni, M. H. Bioorg. Med. Chem. 2010, 18, 3403.

[15] Jin, Y. H.; Liu, P.; Wang, J.; Baker, R.; Huggins, J.; Chu, C. K. J. Org. Chem. 2003, 68, 9012.

[16] Wang, P.; Agrofoglio, L.; Newton, M.; Chu, C. K. J. Org. Chem. 1999, 64, 4173 .

[17] Shuto, S.; Obara, T.; Saito, Y.; Andrei, G.; Snoeck, R.; De, C. E.;
Matsuda, A. J. Med. Chem. 1996, 39, 2392.

[18] Ye, W.; He, M.; Schneller, S. W. Tetrahedron Lett. 2009, 50, 7156.

[19] Palmer, A. M.; Jäger, V. Eur. J. Org. Chem. 2001, 7, 1293.

[20] Chattopadhyay, A.; Tripathy, S. J. Org. Chem. 2011, 76, 5856.

[21] Boyle, G. A.; Edlin, C. D.; Li, Y.; Liotta, D. C.; Morgans, G. L.; Musonda, C. C. Org. Biomol. Chem. 2012, 10, 1870.

[22] Forró, E.; Fülöp, F. Tetrahedron: Asymmetry 2004, 15, 2875.

[23] Liu, C.; Qi, C.; Schneller, S. W. Tetrahedron Lett. 2011, 52, 4931.

[24] Vanden, B. M.; Hylkema, M. N.; Versluis, M.; Postma, D. S. Drugs $R \& D$ 2007, $8,13$.

[25] Diniz, C.; Borges, F.; Santana, L.; Uriarte, E.; Oliveira, J. M. A.; Gonçalves, J.; Fresco, P. Curr. Pharm. Des. 2008, 14, 1968.

[26] Beattie, D.; Brearley, A.; Brown, Z.; Charlton, S. J.; Cox, B.; Fairhurst, R. A.; Fozard, J. R.; Gedeck, P.; Kirkham, P.; Meja, K.; Nanson, L.; Neef, J.; Oakman, H.; Spooner, G.; Taylor, R. J.; Turner, R. J.; West, R.; Woodward, H. Bioorg. Med. Chem. Lett. 2010, 20, 1219.

[27] (a) Wang, J.; Jin, Y.; Rapp, K. L.; Bennett, M.; Schinazi, R. F.; Chu, C. K. J. Med. Chem. 2005, 48, 3736.

(b) Chu, C. K.; Ma, T.; Shanmuganathan, K.; Wang, C.; Xiang, Y.; Pai, S. B.; Yao, G. Q.; Sommadossi, J. P.; Cheng, Y. C. Antimicrob. Agents Chemother. 1995, 39, 979.

[28] Montgomery, J. A.; Shortnacy-Fowler, A. T.; Clayton, S. D.; Riordan, J. M.; Secrist, J. A. J. Med. Chem. 1992, 35, 397.

[29] Wang, J.; Singh, U. S.; Rawal, R. K.; Sugiyama, M.; Yoo, J.; Jha, A. K.; Scroggin, M.; Huang, Z.; Murray, M. G.; Govindarajan, R.; Tanaka, Y.; Korba, B.; Chu, C. K. Bioorg. Med. Chem. Lett. 2011, $21,6328$.

[30] Gadthula, S.; Rawal, R. K.; Sharon, A.; Wu, D.; Korba, B.; Chu, C. K. Bioorg. Med. Chem. Lett. 2011, 21, 3982.

[31] Singh, U. S.; Mishra, R. C.; Shankar, R.; Chu, C. K. J. Org. Chem. 2014, 79, 3917.

[32] Moon, H. R.; Choi, W. J.; Kim, H. O.; Jeong, L. S. Tetrahedron: Asymmetry 2002, 13, 1189.

[33] eong, L. S.; Lee, J. A. Antiviral Chem. Chemother. 2004, 15, 235.

[34] Marquez, V. E.; Hughes, S. H.; Sei, S.; Agbaria, R. Antiviral Res. 2006, 71, 268.

[35] Katagiri, N.; Yamatoya, Y.; Ishikura, M. Tetrahedron Lett. 1999, 40, 9069.

[36] Ji, C.; Miller, M. J. Tetrahedron Lett. 2010, 51, 3789.

[37] Moggio, Y.; Legnani, L.; Bovio, B.; Memeo, M. G.; Quadrelli, P. Tetrahedron 2012, 68, 1384.

[38] Quadrelli, P.; Mella, M.; Legnani, L.; Al-Saad, D. Eur. J. Org. Chem. 2013, 21, 4655.

[39] Tanase, C. I.; Draghici, C.; Caproiu, M. T.; Shova, S.; Mathe, C.; Cocu, F. G.; Enache, C.; Maganu, M. Bioorg. Med. Chem. 2014, 22,513 .

[40] (a) Gordon, R. K.; Ginalski, K.; Rudnicki, W. R.; Rychlewski, L.; Pankaskie, M. C.; Bujnicki, J. M.; Chiang, P. K. Eur. J. Biochem. 2003, 270, 3507.

(b) Maki, A. S.; Kim, T. W.; Kool, E. T. Biochemistry 2004, 43, 1102.

(c) Bennet, L. J.; Brocman, R. W.; Allan, P. W.; Rose, L. M.; Shaddix, S. C. Biochem. Pharmacol. Rev. 1988, 7, 1233.

[41] Montgomery, J. A.; Clayton, S. J.; Thomas, H. J.; Shannon, W. M.; Arnett, G.; Bodner, A. J.; King, I.-K.; Cantoni, G. L.; Chiang, P. K. J. Med. Chem. 1982, 25, 626.

[42] (a) Tseng, C. K. H.; Marquez, V. E.; Fuller, R. W.; Goldstein, B. M.; Haines, D. R.; McPherson, H.; Parsons, J. L.; Shannon, W. M.; Arnett, G.; Hollingshead, M.; Driscoll, J. S. J. J. Med. Chem. 1989, 32,1442 .

(b) Glazer, R. I.; Hartman, K. D.; Knode, M. C.; Richard, M. M.; 
Chiang, P. K.; Tseng, C. K. H.; Marquez, V. E. Biochem. Biophys. Res. Commun. 1986, 135, 688

[43] Jha, A. K.; Sharon, A.; Rondla, R.; Chu, C. K. Tetrahedron 2009, $65,9362$.

[44] Eldrup, A. B.; Prhavc, M.; Brooks, J.; Bhat, B.; Prakash, T. P.; Song, Q.; Bera, S.; Bhat, N.; Dande, P.; Cook, P. D. J. Med. Chem. 2004, 47, 5284.

[45] Thiyagarajan, A.; Salim, M. T.; Balaraju, T.; Bal, C.; Baba, M.; Sharon, A. Bioorg. Med. Chem. Lett. 2012, 22, 7742.

[46] Cho, J. H.; Bernard, D. L.; Sidwell, R. W.; Kern, E. R.; Chu, C. K. J. Med. Chem. 2006, 49, 1140.

[47] Ugliarolo, E. A.; Gagey, D.; Lantano, B.; Moltrasio, G. Y.; Campos, R. H.; Cavallaro, L. V.; Moglioni, A. G. Bioorg. Med. Chem. 2012, 20, 5986

[48] Matyugina, E.; Khandazhinskaya, A.; Chernousova, L.; Andreevskaya, S.; Smirnova, T.; Chizhov, A.; Karpenko, I.; Kochetkov, S.; Alexandrova, L. Bioorg. Med. Chem. 2012, 20, 6680 .

[49] Trost, B. M.; Kuo, G. H.; Benneche, T. J. Am. Chem. Soc. 1988, 110,621.

[50] Cesario, C.; Miller, M. J. J. Org. Chem. 2009, 74, 5730.

[51] Liu, L.-J.; Kim, S. W.; Lee, W. J.; Hong, J. H. Bull. Korean Chem. Soc. 2009, 30, 2989.

[52] Jonckers, T. H.; Lin, T. I.; Buyck, C.; Lachau-Durand, S.; Vandyck, K.; Van Hoof, S.; Vandekerckhove, L. A.; Hu, L.; Berke, J. M.; Vijgen, L.; Dillen, L. L.; Cummings, M. D.; de Kock, H.; Nilsson, M.; Sund, C.; Rydegard, C.; Samuelsson, B.; Rosenquist, A.; Fanning, G.; Van Emelen, K.; Simmen, K.; Raboisson, P. J. Med. Chem. 2010, 53, 8150 .

[53] Li, H.; Yoo, J. C.; Hong, J. H. Bull. Korean Chem. Soc. 2011, 32, 1146.

[54] Choi, T. H.; Ahn, S. H.; Kwon, H. C.; Choi, C. W.; Awh, O. D.; Lim, S. M. Appl. Radiat. Isot. 2004, 60, 15.

[55] Alauddin, M. M.; Shahinian, A.; Park, R.; Tohme, M.; Fissekis, J. D.; Conti, P. S. J. Nucl. Med. 2004, 45, 2063.

[56] Ahn, H.; Choi, T. H.; Castro, K. D. A.; Lee, K. C.; Kim, B.; Moon,
B. S.; Hong, S. H.; Lee, J. C.; Chun, K. S.; Cheon, G. J.; Lim, S. M.; An, G.; Rhee, H. J. Med. Chem. 2007, 50, 6032.

[57] Ahn, H. S.; An, G. I.; Rhee, H. J. Bull. Korean Chem. Soc. 2011, $32,1931$.

[58] (a) An, G.; Rhee, H. Nucleosides, Nucleotides Nucleic Acids 2003, $22,437$.

(b) Ahn, H.; Choi, T. H.; Castro, K. D. A.; Lee, K. C.; Kim, B.; Moon, B. S.; Hong, S. H.; Lee, J. C.; Chun, K. S.; Cheon, G. J.; Lim, S. M.; An, G.; Rhee, H. J. Med. Chem. 2007, 50, 6032.

[59] Kato, A.; Yasuda, Y.; Kitamura, Y.; Kandeel, M.; Kitade, Y. Parasitol. Int. 2012, 61, 501.

[60] (a) MacKeith, R. A.; McCague, R.; Olivo, H. F.; Roberts, S. M.; Taylor, S. J.; Xiong, H. Bioorg. Med. Chem. Lett. 1994, 2, 387.

(b) An, G. I.; Rhee, H. J. Nucleosides, Nucleotides Nucleic Acids 2002, 21, 65 .

[61] Noguchi, Y.; Yasuda, Y.; Tashiro, M.; Kataoka, T.; Kitamura, Y.; Kandeel, M.; Kitade, Y. Parasitol. Int. 2013, 62, 368.

[62] (a) Agrofoglio, L. Curr. Org. Chem. 2006, 10, 333.

(b) Shahan, M. A. E.; Nasr, A. Z. Adv. Heterocycl. Chem. 1997, 68, 223.

(c) Shaban, M. A. E. Adv. Heterocycl. Chem. 1998, 70, 163.

[63] (a) Fissekis, J. D.; Markert-Creegan, B. J. Org. Chem. 1967, 32, 3595 .

(b) Fissekis, J. D.; Markert-Creegan, B. J. Org. Chem. 1966, 31, 2945.

[64] Rao, J. R.; Schinazi, R. F.; Chu, C. K. Bioorg. Med. Chem. 2007, 15,839 .

[65] (a) Jin, Y. L.; Hong, J. H. Bull. Korean Chem. Soc. 2005, 26, 1366. (b) Oh, C. H.; Liu, L. J.; Hong, J. H. Nucleosides, Nucleotides Nucleic Acids 2008, 27, 1144.

[66] Hřebabecký, H.; Nencka, R.; Šála, M.; Dejmek, M.; Dračínský, M.; Holý, A. Synthesis 2010, 23, 4119.

[67] Shealy, Y. F.; Clayton, J. D. J. Am. Chem. Soc. 1966, 88, 3885.

[68] Guo, X.-H.; Liu, C; Zheng, L.-X; Jiang, S.-D.; Shen, J.-X. Synlett 2010, 1959. 